\title{
Jason-2 in DUACS: Updated System Description, First Tandem Results and Impact on Processing and Products
}

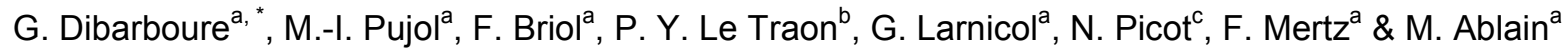 \\ ${ }^{a}$ Collecte Localisation Satellites (CLS), Space Oceanography Division, Ramonville St-Agne, France \\ ${ }^{\mathrm{b}}$ Institute Français de Recherche pour l'exploitation de la Mer (IFREMER), Plouzané, France \\ ${ }^{c}$ Centre National d'Etudes Spatiales (CNES), Toulouse, France \\ *: Corresponding author : Gerald Dibarboure, email address : gerald.dibarboure@cls.fr
}

\begin{abstract}
:
For more than 13 years, the multisatellite DUACS system has been providing the altimetry community with Near Real Time and Delayed Time products ranging from reduced GDR (also known as CorrSSH) to along-track Sea Level Anomalies (SLA) and multimission Maps of Sea Level Anomalies (MSLA). A post-Jason-2 description of the DUACS system is given, with input data, processing and products, and a focus on the DT-2010 reprocessing involving a total of almost 60 years worth of altimetry data from GEOSAT to Jason-2.

Less than one month after launch, Jason-2 proved to be a strong asset for multisatellite applications as it was able to replace Jason-1 as the reference mission in DUACS. Furthermore, the new Jason-2/Jason-1 tandem configuration provides an unprecedented duo for mesoscale and circulation observation. More generally, the quality of Jason-2 has a large impact in DUACS on a number of fronts: in the continuity of the reference mission for climate applications exploiting DUACS products, in the new multi-reference orbit error reduction scheme, or for new metrics derived from a Degrees of Freedom of Signal analysis applied to the multimission mapping. This paper gives an overview of the many impacts of the integration of Jason-2 into DUACS.
\end{abstract}

Keywords : Jason-2, DUACS, multimission, altimetry, DFS, cross-calibration, reference mission, Jason tandem 


\section{Introduction}

The multi-mission processing of altimeter data was developed by CLS as part of D.U.A.C.S (Developing Use of Altimetry for Climate Studies), a European Commission project which started in February 1997. DUACS was a shared cost project, part-funded under the CEO Programme of the Environment and Climate. It was coordinated by CLS and gathered four of the major climate research teams in Europe: ECMWF, U.K.Met.Office, Cerfacs and the MaxPlanck Institute for Meteorology. The 3-year projectês purpose was to demonstrate that climate applications could be operationally served by multi-mission altimetry data in near real time.

Since the end of the original project, the Near Real Time (hereafter NRT) and Delayed Time (hereafter DT) components have continued to serve operational oceanography and climate forecasting projects. Thirteen years after the original prototype, the system has been redesigned and significantly upgraded many times as the knowledge of altimetry processing has been refined and as the oceanography needs evolved. It is now part of the CNES multimission ground segment SSALTO. It is also the backbone of the Sea Level Thematic Assembly Center of the European project MyOcean, and it provides data and algorithms to

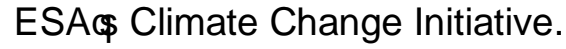

DUACS features multi-mission products based on all altimetry satellites from GEOSAT to Jason-2 for a total of 60 years of cumulated data as shown in figure 1. In Near Real Time,

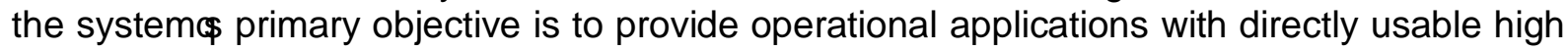
quality altimeter data from all missions in operations. In Delayed Time, it is to maintain a consistent and user-friendly altimeter climate data record using the state-of-the-art recommendations from the altimetry community.

DUACS is an operational production system, and the name of a family of so-called Level2P to Level4 altimetry products (as defined in section 0 ). These products are distributed and documented by AVISO, the CNES altimetry dissemination center. AVISO also provides an extensive user support and service desk to DUACS products. For this reason DUACSô products are sometimes erroneously referred as ñA VISO mapsòin the literature.

Section 2 gives an updated description of DUACS, from input data to processing and output products. Section 3 focuses on the integration of Jason-2 and the Jason-2/Jason-1 tandem with highlights on the recent DT-2010 reprocessing, and section 4 on the long term impact of having Jason-2 in DUACS.

\section{DUACS: system and products}

\subsection{Data used}

The main input data of DUACS is the so-called Level2 (L2) altimeter product, or Geophysical Data Record (GDR). The L2 product comes in three forms with increasing delivery delay: Fast Delivery products (a.k.a OGDR), Intermediate products (a.k.a IGDR), and Delayed Time products (a.k.a GDR). DUACS uses all three types of data in its NRT and DT sub-systems.

GDR data benefit from the best quality, notably in terms of orbit determination. Produced by NASA or CNES (TOPEX/Poseidon, Jason-1, Jason-2), ESA (ERS1, ERS2, ENVISAT), or NOAA (GEOSAT, GFO), GDR products are the input data of DUACS Delayed Time processor. 
The timeliness of these products is not compatible with Near Real Time constraints, so in place of GDRs, the NRT processor uses primarily IGDR data. This L2 product is generally produced in 1 to 3 days, and the database is completed with OGDR products (also known as FDGDR or FDMAR products for ENVISAT and OSDR for Jason-1) as the latter are produced in only a few hours. GDR, IGDR and OGDR datasets are based on the same instrumental measurements, but their quality is different. Produced in near real time (a few hours) by the same agencies (adding Eumetsat and NOAA for Jason-2), Fast Delivery products do not always benefit from precise orbit determination, nor from some external model-based corrections (e.g. Dynamic Atmospheric Correction, GPS-derived ionospheric correction).

Standards and processing used for GDR products are heterogeneous as they are decided by different agencies, Joint Steering Groups, or different subsets of altimetry experts. Moreover the cost of Level0 to Level2 reprocessing campaigns makes it impossible to have fully consistent and up-to-date datasets on all missions at all times. For instance, the ESA project REAPER intends to perform the first end-to-end reprocessing of ERS1 and ERS2 (19912010) with ENVISAT GDR-B standards. Until this project is complete (late 2011) official ERS GDRs still use standards set up in the nineties.

Yet homogeneity is a strong requirement from most altimetry users. Therefore it is necessary to complement GDR datasets with ancillary datasets ranging from updated instrumental corrections (e.g. radiometer drift correction, alternative retracking, better ultra-stable oscillator correction...), or orbit solutions, to geophysical corrections (e.g. tidal models, model-based ionosphere or atmospheric corrections) and reference surfaces (e.g. Mean Sea Surface or ice/land/ocean mask). This is particularly true for OGDR data as the operational production from Agencies cannot afford to wait for some external datasets. DUACS operationally acquires and applies about 30 different types of ancillary data. Some of them are exploited in the SLA product (see next sections) whereas others are only used for validation and cross-comparison purposes.

\subsection{Data processing}

This section gives a post-Jason-2 description of DUACS data processing. At this point, it is relevant to point out that new versions of DUACS are released every 3 to 6 months. The project web pages [AVISO, 2010c] provide an updated source of information about new releases and processing changes.

\subsubsection{Standard DT Processing}

The processing sequence in DUACS can be divided into 7 main steps: acquisition, homogenisation, input data quality control, multi-mission cross-calibration, along-track SLA generation, multi-mission mapping, and final quality control.

\subsubsection{Acquisition and pre-processing}

The acquisition is a twofold process. The first step is a straightforward retrieval and reformatting of altimeter data and dynamic ancillary data from external repositories: ECMWF meteorological model outputs, GPS-derived total electron content grids from Jet Propulsion Laboratory, NRT atmospheric corrections derived from the barotropic ocean model MOG2D from LEGOS. The second step is the synchronisation process. As mentioned above, altimeter datasets require various ancillary data to be processed. If ancillary data flows are missing or late, the synchronisation engine put altimeter data flows with missing ancillary data in waiting queues because they cannot be processed. The synchronization engine automatically unfreezes altimetry flows upon reception of the missing ancillary data. Corrupted, duplicate or reprocessed data are also detected and frozen with a warning to the DUACS operators. Data flows that are successfully processed are stored into the along-track 
reference database. Although the scientific value of the Acquisition process is non-existent, it is extremely important from an operational and data management point of view.

The homogenisation process consists of applying the most recent corrections, models and references recommended for altimeter products (by agencies, or expert groups such as

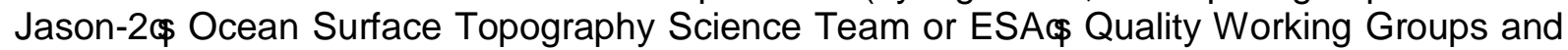
Experts Support Laboratories). Each mission is processed separately as its needs depend on the base input (O/I)GDR. The up-to-date list of corrections and standards applied in RT, NRT and DT productions are given in the latest DUACS product handbook [AVISO 2010b].

The Input Data Quality Control (QC) is a critical process applied to guarantee that DUACS uses only the most accurate altimeter data. This process is intricately linked with the extensive calibration/validation activities carried out by CLS for CNES or ESA: mono-mission $\mathrm{Cal} / \mathrm{Val}$, multi-mission cross-calibration, comparison to Tide Gauges, comparison to T/S insitu data from ARGO... The input data QC is composed of a traditional editing process which applies various algorithms to automatically detect spurious measurements, and a long term monitoring of L2 products to detect and to fix more subtle errors (e.g. drifts, offsets associated with manoeuvres or instrument change).

The automated editing process generally rejects a small percentage of altimeter measurements, but these erroneous data could be the cause of a significant quality loss, notably in the coastal band. In addition to simple quality flags or parameter thresholds, various algorithms are deployed to try and detect erroneous data: comparison to local dynamics, discontinuity detection, abnormal statistics per data flow, and cross-comparison between concurrent sensors. The up-to-date editing process is described in annual $\mathrm{Cal} / \mathrm{Val}$ reports from each mission [AVISO 2010a].

The long term $\mathrm{Cal} / \mathrm{Val}$ or cross-calibration, and comparison to in-situ activities carried out for CNES or ESA, are the source of more than 40 project reports, publications or talks in altimetry meetings every year [e.g. Ablain et al 2009, Ablain et al 2010, Faugere et al 2006, Ollivier et al 2010, Mertz et al 2010]. Technically, DUACS and Cal/Val are independent from one another, but the input data QC from DUACS is performed by the same team, with the same tools, and on a common Sea Level Climate Database. The synergy between validation and product generation speeds up the decision process which is a key success factor in a quality oriented and cost-efficient service as duplication is non-existent, and as CalVal scientific findings translate into user-oriented changes of the DUACS processors.

The multi-mission cross-calibration process ensures that all data flows from all satellites provide consistent and accurate information. Raw $L 2$ datasets are not always coherent, even when properly homogenized and edited. Indeed, there are various sources of geographically correlated error patterns, ranging from instrument and processing error residuals to orbit standards. Even for recent missions such as ENVISAT, the difference with Jason-1 and Jason-2 can be as high as $5 \mathrm{~cm}$, with wavelengths ranging from $1000 \mathrm{~km}$ to basin-wide signatures (from crossover differences on figure 2, top left map). Only the so-called ñeferenceò missions agree to within $2 \mathrm{~cm}$ or even $1 \mathrm{~cm}$ : Jason-2, Jason-1, and to some extent T/P (with the latest orbit solutions from the GSFC group, and Sea Surface Height corrected from biases and first order waveform leakages) [Ablain et al 2009, Faugere et al 2006, AVISO 2010a]. The purpose of the cross-calibration process is to use empirical processes to minimize geographically correlated error patterns. Although the sequence is rather complex, two algorithms account for the bulk of the error minimization: the Orbit Error Reduction (hereafter OER) and the Long Wavelength Error Reduction (hereafter LWER).

The OER is a two-step cross-calibration process. The first step is a global crossover minimization performed only on the so-called reference mission. TOPEX/Poseidon was the first reference mission, then Jason-1 replaced it, to be in turn replaced by Jason-2. The 
crossover minimization performed on the reference mission is derived from [Tai, 1988] and it uses a one and two cycle per revolution analytical model. The minimization is performed on overlapping time windows of a few hours.

The second OER step is a dual crossover minimization of each other satellite. It is derived from [Le Traon et Ogor, 1998]. Two types of crossover differences are globally minimized using spline functions: RxS, and SxS, where $R$ is the reference mission, and $S$ is the other mission (e.g. ENVISAT). Historically, this method was developed for missions that did not have an accurate orbit determination (ERS and GFO). Using the OER process, the orbit precision of any satellite can be improved almost to the level of the reference mission. This process is particularly efficient in the open ocean and at latitudes lower than $66^{\circ}$ (T/P, Jason, Jason-2 latitude limit) due to the lack of pre-defined analytical model. The downside is that splines become less accurate in enclosed seas, coastal areas and at higher latitudes as they are not well-constrained on land or above $66^{\circ}$ (few or no crossovers).

The LWER is therefore used as a second cross-calibration process. It is derived from [Le Traon et al, 1998, and Ducet et al, 2000]. An optimal interpolation process is used to estimate and remove local biases between neighbouring ground tracks from each satellite. The algorithm requires a good statistical description of the problem to be solved: sea level variability that should be ignored because it not LWE error, localized correlation scales, mission-specific noise, and variance of the LWE to be removed (defined from an analysis of one year of data from each mission). This empirical process absorbs geographically correlated errors between different sensors (residual orbit error, instrumental biases, residual artefacts from calibration differences), but also large scale / high-frequency signals not accounted for by other corrections (e.g. tides, barotropic response to atmosphere signals).

Thus, the consequence on DUACS is not trivial as high-frequency + long wavelength content is, by construction and purposely, removed from any product where this processing is applied. To that extent, along-track products from DUACS are generated in two versions: with the LWER applied and without the LWER applied (see DUACS product handbook [AVISO, 2010b]). Conversely, multi-mission maps require this process to be applied as it is necessary to enforce a full coherency between sensors, and because altimetry constellations with less than 5 satellites cannot resolve such rapid signals anyway. Simulations show that we need a minimum of 12 simultaneous altimeter missions to correctly resolve the rapid, long wavelength ocean dynamicsò(typically $1000 \mathrm{~km}$ and $24 \mathrm{~h}$ ).

\subsection{Global Product Generation}

The along-track Sea Level Anomaly product generation (or repeat track analysis) is necessary for two reasons: the poor knowledge of small scales of the geoid, and the necessity to build co-located time series. For both reasons, it is necessary to perfectly colocate Sea Surface Height data and to subtract a time average of similarly processed data. The reference time period used by DUACS is 1993-1999. The SLA computation is composed of various steps: projection on the repetitive track, correction of the cross-track geoid gradient, removal of the time average, cross-validation of the Sea Level Anomaly content.

Altimetry satellites generally use repetitive orbits: after 10 to 35 days, the sensor flies over the same locations, hence the notion of cycles (time needed to revisit the same location) and the ability to co-locate data. But the satellite ground track cannot be perfectly controlled and it is kept only in a band about $1 \mathrm{~km}$ wide. It is thus necessary to use an arbitrary and missionconsistent position for the co-location process. SSH measurements are then projected onto these co-location points. Precise cross-track projection and/or interpolation schemes are required to avoid errors of 1 to $3 \mathrm{~cm}$ (e.g. geoid signal blurred, interpolation or high-frequency errors and noise). Dorandeu et al (2003) also showed that this process must exploit a good knowledge of the local cross-track geoid gradient (CTGG) to avoid an error of 2 to $3 \mathrm{~cm}$ RMS. 
The next step to compute along-track Sea Level Anomalies is to subtract the so-called Mean Profile (hereafter MP). The simplest MP are time averages of similarly co-located SSH data from the same ground track. But there are downsides to this simple approach: missionspecific discrepancies due to interannual variability $(2$ to $5 \mathrm{~cm}$ in the 500 to $800 \mathrm{~km}$ band, 2 to $5 \mathrm{~cm}$ basin-wide biases), absorption of 1 to $7 \mathrm{~cm}$ mesoscale variability error in the average if the time series is less than 200-300 cycles (equivalent to 7 years for the Jason-2 track, 25 years for the ENVISAT track). To that extent, the modern computation of a MP [Le Traon and Dibarboure, 2004] is slightly more complex with an iterative process where oceanic variability is minimized from the SSH (before co-location) using a priori knowledge from Sea Level maps derived from previous iterations or from other missions, interannual discrepancies are also accounted for: MPs are computed on the whole mission duration but re-referenced -a posteriori- onto 1993-1999 for the sake of coherency with other missions.

For some missions, the repeat track analysis cannot be used: Cryosat-2, GEOSAT or ERS1 (during their respective geodetic phases). The same stands for the first 3-5 years of any future mission flying on a new ground track. The alternative is to use a gridded Mean Sea Surface (MSS) instead. For geodetic data, DUACS uses the recent CNES/CLS 2010 MSS (Schaeffer et al 2010) as it was computed from the same data, time reference, ocean variability minimization, and software as the ones used for traditional DUACS mean profiles, hence minimizing discrepancies between SLA from the repeat track analysis and SLA derived from the geodetic proxy.

But using any gridded Mean Sea Surface along an unknown satellite track adds new error sources to the reference errors already present in Mean Profiles. For example, the mesoscale signal may not be not properly removed from the MSS away from repetitive tracks, correlated errors are absorbed into the MSS, the geoid signal is smoothed by the mapping process, and there are geoid omission errors from the lack of altimetry data.

The comparison of independent data to gridded MSS computed before 2008 points to a 3 to $7 \mathrm{~cm}$ error [Dorandeu et al 2004, Ablain et al 2010]. Results from more recent gridded MSS (differences observed between surfaces from the Danish National Space Center and CNES/CLS, comparison between gridded MSS and MPs, formal mapping error associated with the MSS gridding process from CNES/CLS) highlight the great improvement observed on recent MSS with a global error ranging from 2 to $5 \mathrm{~cm}$. However, the MSS is built from Mean Profiles and geodetic data, so the additional SLA error stemming from the use of a gridded MSS in place of a repeat track analysis directly adds to the error already in Mean Profiles.

DUACS uses Mean Profiles for TOPEX/Poseidon, Jason-1, Jason-2, ENVISAT, ERS2, ERS1 (repetitive phase). The gridded MSS proxy was used for the geodetic phase of ERS1, and it will be used for upcoming geodetic missions or phases (Cryosat-2, HY-2A geodetic phase) as well as during the first 3-5 years of any future mission flying on a new ground track: ENVISAT extended phase, Jason-1 Extension of Life phase, HY-2A repetitive phase, Sentinel-3, and possibly Jason-CS (assuming the historical T/P orbit is not used).

After the repeat track analysis (or the geodetic proxy), a cross-validation technique is used as the ultimate screening process for isolated and slightly erroneous measurements. SLA flows are compared to previous and independent SLA data sets using a 12 year climatology and a 3 sigma criteria for outlier removal.

Although the along-track SLA product can be used rãs isò a smoothed+subsampled variant is created for three reasons: 1/ to filter out the altimetric ñed noiseòdescribed by Stammer (1997), 2/ to filter out short scale oceanic signals which cannot be globally resolved by constellations of 2 to 4 sensors, and 3 / to reduce the computing load of DUACS users that do 
not require the full altimetric resolution. The subsampled dataset is notably used in the multimission mapping (see below). The filter applied is an along-track Lanczos filter with a geographically dependent cut-off wavelength: it ranges from $250 \mathrm{~km}$ in the equator band to $60 \mathrm{~km}$ above $40^{\circ}$. The wavelength model and the subsampling pattern used are coherent with the correlation scales used in the mapping process which are derived from model fits on actual data [Le Traon et al, 2003]. The filtered dataset should not be used by DUACS users who want to study small features, and notably in the coastal domain (where kernel filters can contaminate the SLA). To that extent, non-filtered and non-subsampled SLA products are also distributed on AVISO and should be preferred for such applications.

The multi-mission mapping process is based on an optimal interpolation derived from [Le Traon et al, 1998], with various improvements [e.g. Ducet et al, 2000; Le Traon et al, 2003; AVISO, 2010c]. The method requires a priori knowledge of the covariance of sea level and measurement errors. Sea Level covariance functions and error budgets are derived from an analysis of T/P, Jason-1 and ERS data [Le Traon et al., 2003]. Arguably the most critical parameters used in the mapping are the signal covariance and propagation models as they largely control the scales observed on DUACS maps (along with the along-track filtering mentioned above). The covariance and propagation models used in the global mapping are geographically dependent with temporal scales ranging from 10 to 40 days, meridional scales ranging from 100 to $300 \mathrm{~km}$, zonal scales ranging from 150 to $450 \mathrm{~km}$, meridional propagations ranging from -7 to $7 \mathrm{~km} /$ day, and zonal propagations ranging from -20 to 10 $\mathrm{km} /$ day. The geographical distribution is in line with (but strictly not identical to) observations from Jacobs et al (2001) and the difference are due to differences in computation procedures.

Although it is technically possible to compute maps with much shorter scales (notably regional maps, and during the period with 3 or 4 concurrent altimeters), these parameters are the best global trade-off to achieve global resolution of mesoscale. In other words, oceanic structures are coherently observed from one map to the next whereas shorter correlations models would be observe small features only locally (wherever + whenever an along-track altimeter sample is located): a pure optimal interpolation is technically barely able to properly reconstruct the whole life-cycle of such small mesoscale features (time of appearance, correct evolution of shape and amplitude, movement, time of disappearance). The input observation needed is simply not available [Greenslade et al, 1997; Le Traon and Dibarboure 2003]. Larger constellations or more complex gridding techniques (e.g. with better knowledge of the local ocean dynamics), or high-resolution ocean models only can complement the altimetry sampling which cannot resolve small structures alone.

DUACS maps are computed on a daily basis on a $1 / 3^{\circ} \times 1 / 3^{\circ}$ Mercator grid (i.e. same resolution in latitude and longitude that is approximately equal to $33 \mathrm{~km}$ times the cosine of latitude) and on $0.25^{\circ} \times 0.25^{\circ}$ Cartesian grid, with regional variants computed at higher resolution (e.g. $0.125^{\circ}$ in the Mediterranean Sea, or in the Black Sea). Maps of Absolute Dynamic Topography (MADT) are then built from the sum of the map of SLA and the Mean Dynamic Topography CNES/CLS 2009 [Rio et al, 2010].

Furthermore, in Near Real Time, the difficulty is that the time window available for alongtrack data is not centered on the map date. The more recent the NRT map the higher the NRT error, as characterized by Pascual et al (2008). The timeliness vs quality trade-off is tricky as some operational applications want the former, whereas scientific studies need the latter. Therefore three sets of maps are computed every day: draft maps with a timeliness better than 24h $\left(D_{0}+0 d\right)$, consolidated maps at $D_{0}+3 d$ (draft maps computed three days before are overwritten with higher quality), and final NRT maps at $D_{0}+6 \mathrm{~d}$ (consolidated maps computed three days before are overwritten with higher quality NRT maps). This updating process is computationally more intensive, but it gives the advantages of both worlds: best 
timeliness because recent maps are available as soon as possible, and good quality because the product is consolidated when more NRT data become available for the OI.

\subsection{OGDR Pre-processing}

The orbit determination error on OGDR products is much larger than on IGDR products, and the standard cross-calibration is not sufficient to remove all this error. IGDR are delivered within 1 day to 3 days in nominal operations. On the one hand, adding innovative information in the multi-satellite map is exceedingly important for a better NRT resolution of rapid mesoscale features [Pascual et al, 2008], on the other hand the very large scale $(5000 \mathrm{~km}$ and larger) oceanic signals barely benefit from additional data as their correlation scales is much larger than $48 \mathrm{~h}$. It is thus possible to extract the short scale innovative content in OGDR datasets and to ignore large scale signals affected by orbit error, assuming that they can be observed from 2-day old IGDR.

In a nutshell, the OGDR process used by DUACS is to apply a high-pass filter (Lanczos, $750 \mathrm{~km}$ ) and to merge this content with low-pass filtered MSLA maps based on IGDR data only, thus creating an hybrid IGDR/OGDR dataset whose quality is sufficient to derive standard SLA products. The hybrid data are then cross-calibrated like IGDR data, albeit in different pipelines with adjusted error bars (e.g. larger error budget in the LWER).

Adding up to $48 \mathrm{~h}$ of OGDR product from three missions ( 150 tracks) to the IGDR data allows the mapping process to observe a significant part of the variability lost by the noncentered time window in NRT, and to recover up to $40 \%$ of the information lost from DT configuration (data from the future are available to the OI) to NRT mode (data from the future not available). Comparison between IGDR+OGDR maps and equivalent DT maps highlighted that the orbit error from OGDR was properly controlled by the filtering process.

Note that Jason-2 real time orbit solutions feature an unprecedented accuracy: both the onboard Diode orbit determination from CNES [Jayles et al, 2010], and the quasi-real time GPS orbit solutions from JPL/NASA [Haynes et al, 2010] can achieve an orbital determination as good as the NRT (or IGDR) solutions of previous missions. To that extent, the DUACS OGDR process will be upgraded in future versions to exploit this Jason-2 achievement.

\subsection{Products}

As illustrated by the reference list, or the DUACS website (AVISO 2010b), there is a large diversity of applications and objectives in the one thousand DUACS user groups worldwide: operational oceanography [Le Traon et al 2009, Bell et al 2009, Johannessen et al 2006], climate [Balmaseda et al 2010, Willis 2010, Prandi et al 2009], mesoscale [Chelton et al 2010, Morrow et al 2010, Fu 2009], interannual variability [Qiu and Chen 2010], Rossby waves [Cipollini et al 2006], surface currents [Johnson et al 2007], or lagrangian analyses [d'Ovidio 2009]. It is however not possible to serve all applications with a single product, resolution or processing.

There are three families of DUACS products with increasing complexity: multi-mission maps (Level4 or L4), along-track pre-computed products (Level3 or L3), and reduced GDR (Level2P or L2P). Each product is delivered either as a Sea Surface Height anomaly to the 93-99 reference, or as an absolute content. For the latter, the Mean Dynamic Topography from [Rio, 2009] is used as a reference.

Multi-mission maps merge the information from all satellites in a very accessible format and content. DUACS produces maps with various resolutions and content (MSLA, MADT, maps of formal error, geostrophic velocities derived from the SSH). There are two families of SLA maps: the so-called r̃eferenceò series (REF) and the ñp-to-dateò series (UPD). The latter 
uses all sensors available, resulting in maps from two satellites in 1993-2000 to three or four satellites (GFO and TP/Jason tandems) from 2000 to present time, while the former is based on a constant 2-satellite sampling from 1993 to present time (homogeneous quality, but subpar accuracy from 2000 onwards). The UPD thus features the best multi-satellite maps at the price of non-constant sampling capability [Le Traon and Dibarboure 2002, Pascual et al 2006]. On the contrary, the REF series is less accurate but probably preferable for studying interannual variability of mesoscale processes thanks to the homogenous quality throughout the entire record (less affected by satellite sampling changes).

Pre-computed along-track SLA products are the simplest directly usable altimetry products for users who want to exploit the actual along-track sampling. They are delivered with various contents (SLA, Absolute Dynamic Topography), and with various resolutions (from filtered/subsampled products to the full unfiltered $1 \mathrm{~Hz}$ resolution), and with various processing (e.g with and without high-frequency content removed by the LWER process).

Reduced GDRs (a.k.a CorrSSH) are the most complex products as they provide the same type of content as traditional GDRs. The main difference with GDRs is that the CorrSSH contains only the parameters needed for the computation of a user-custom SSHA content (no instrumental or environmental parameters), and most importantly that all missions feature consistent formats (COARDS-compliant netCDF) and standards (see section 0 ). This product is aimed at experimented users who want a consistent and up-to-date altimetry baseline, but also the ability to change specific corrections and references or to ignore specific DUACS processing algorithms (e.g. editing or cross-calibration). Contrary to various GDR-like products released by non-Agency production centers, all fields and corrections are documented and fully supported by the AVISO user service.

Figure 4 illustrates the coverage one might expect from the along-track SLA product. The size of each circle shows the local correlation between co-located times series from ENVISAT (full $1 \mathrm{~Hz}$ resolution) and an arbitrary WOCE tide gauge series (\#129, Portland, Australia). Bathymetry lines are also given as they partly dictate the local consistency between these two types of observations: the correlation is higher than 0.8 in shallow waters and lower than 0.5 in deep waters.

Figure 5 illustrate the MADT gridded product merging Jason-2+Jason-1+ENVISAT in the Gulf Stream on 2010/07/01. Eddies and meanders are clearly visible in Near Real Time. Streamlines from lagrangian tracers are superimposed in black to highlight strong gradients and the mean current. Their trajectory is derived from DUACSôgeostrophic velocities and a fourth order Runge-Kutta integrator.

\section{Jason-2/Jason-1 tandem results}

\subsection{First Jason-2 experiment}

One month after the launch of Jason-2, Jason-1 suffered from a major onboard anomaly resulting in a unusually large Near Real Time data gap (time needed to investigate and to resume nominal operations): the mass memory event occurred on 2008/08/13 and the IGDR production restarted on 2008/08/22 [AVISOe]. At the time, only Jason-1 and ENVISAT were in nominal and commissioned status. GFO was still operated, albeit with a severely degraded coverage (50\%). The anomaly on Jason-1 was thus critical for the multi-satellite system DUACS because: 1/only one mission and a half were still delivering operational NRT data, and 2/ Jason-1 IGDR data were the reference used to minimize orbit errors on both ENVISAT and GFO (see section 0). The weakened state of the altimetry constellation could have resulted in the complete stop of DUACS operations for the first time since 1998. 
Fortunately, Jason-2 had already demonstrated that it was able to provide high quality Near Real Time data (CalVal splinter, proceedings of OSTST 2008), but it was still in Cal/Val phase. As an exceptional and temporary measure, DUACS was authorized to use Jason-2 data until the end of the investigation on Jason-1. Thanks to efficient interactions between Cal/Val actors and DUACS, Jason-2 was integrated into DUACSôNRT processor in a few days only, thus sustaining L3 along-track data and L4 multi-mission map productions for about 2 weeks. Upon the end of the Jason-1 investigations, Jason-2 datasets were then replaced by Jason-1 products.

Figure 6 illustrates this event with a map of the difference between an ENVISAT+GFO map in the Mediterranean Sea and the same product based on Jason-2+ENVISAT+GFO. Large $100-200 \mathrm{~km}$ patches in black highlight differences that are higher than $5 \mathrm{~cm}$. These differences are not trivial in the area since the oceanic variability of the Mediterranean Sea generally ranges from 5 to $10 \mathrm{~cm}$. Mesoscale features were often missed entirely with only the near real time coverage of ENVISAT $+50 \%$ GFO. Further analyses on DT products (see section 0) showed that the added sampling from Jason-2 allowed to better observe actual mesoscale features (not artefacts) in a continuous and coherent way.

These improvements had been shown in offline studies from Pascual et al $(2006,2008)$, but for the first time in 13 years of DUACS operations, they were observed on actual, operational, and Near Real Time multi-satellite products, and only one month after the launch of Jason-2. This feat was possible because: 1/ IGDR product were made available to operational users before the end of the commissioning phase (with disclaimers about quality), 2/ the first weeks of $\mathrm{Cal} / \mathrm{Val}$ activities found no show-stopping anomaly on the first datasets and provided a documented feedback on minor anomalies that could be postprocessed by L2 users.

\subsection{Jason-2 and the new tandem configuration}

For six months after the initial Jason-2 experiment in DUACS, Jason-2 was not used by

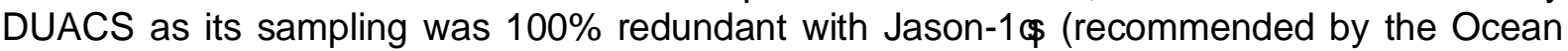
Science Topography Science Team for Calibration / Validation purposes.). Jason-2 was reintegrated in the NRT processor of DUACS after the end of its CalVal phase in early 2009, and more precisely in February before Jason-1 was moved to the interleaved ground track.

The Jason-2/Jason-1 tandem is derived from the historical interleaved configuration used from 2002 to 2005 with Jason-1 and TOPEX/Poseidon, but a new phasing configuration was adopted for the Jason-2/Jason-1 interleaved phase, as shown in Figure 7. The historical Jason-1/TP configuration (Figure 7a) had both satellites flying in parallel, separated by approximately $150 \mathrm{~km}$ ( $18^{\circ}$ angular lag in the orbit plane). The upside of this configuration was that it was locally optimal wherever and whenever the dual-observation was located. It also made the direct observation of geostrophic velocities possible as in Stammer and Theiss (2004). The weakness of this configuration was that no data whatsoever was locally provided for 10 days after that. Furthermore, the sampling propagation direction was dictated by the T/P sampling pattern (3-day cycles propagating eastward) and prone to aliasing. Eastward propagating signals advected by strong zonal currents such as the Gulf Stream or Kuroshio were not observed in the same way as the majority of the ocean $\hat{\boldsymbol{\Phi}}$ westward propagating signals. More importantly, both satellites were providing redundant datasets for the observation of large and rapid signals typically involved in $\mathrm{SWH}$ or storm surge applications.

The new configuration uses the same interleaved track but it is dynamically very different as Jason-2 and interleaved Jason-1 are separated by $1350 \mathrm{~km}\left(162^{\circ}\right.$ angular lag in the orbit plane). As a result, the interleaved Jason-1 track is located next to Jason-2 with an apparent 
5-day shift (Figure 7b). There are three advantages to this configuration: it is slightly better in terms of global aliasing albeit not on par with the ideal 3.5-day offset configuration [Tai, 2009], it is slightly westwards propagating, and it is slightly more efficient in terms of near real time observation as measurements from the same dates are as far away as possible.

The latter is primarily significant for SWH or storm surge applications as large and rapid signals are to be observed in real time. For instance, the probability of detecting in less than $24 \mathrm{~h}$ a $1000 \mathrm{~km}$ wide feature located randomly in the Atlantic is $80 \%$ for the Jason-1/TP configuration, and $96 \%$ for the Jason-2/Jason-1 configuration. For the sake of comparison, in the same conditions, the non-coordinated constellation Jason-1+ENVISAT+GFO has $97 \%$ chance to detect the same feature. Synchronization and phasing are the key.

The same is true to a lower extent for mesoscale signal, as it is possible to find at least one past observation within $150 \mathrm{~km}$ and 5 days in both directions, and a homogeneous amount of samples in any $500 \mathrm{~km}$ and 4-day sampling window. The consequence is that the probability to detect a $150 \mathrm{~km}$ wide feature in less than 5 days (e.g. near real time operational applications) is $85 \%$ for the historical configuration and $90 \%$ for Jason-2/Jason-1, and $92 \%$ for Jason-1+ENVISAT+GFO. The improvements associated with the interleaved tandem changes are detailed in [Dibarboure et al, 2008] where animations make the dynamical sampling changes much more intuitive.

\subsection{Improvement of DUACS products with Jason-2 and the new tandem}

\subsubsection{Impact on MSLA maps and multi-sensor statistics}

Adding Jason-2 to DUACS had strong impact on multi-satellite maps as expected from theoretical analyses [Le Traon and Dibarboure, 2002] and from past interleaved multimission product analysis [Le Traon and Dibarboure, 2004; Pascual et al 2006].

Figure 8 shows the first map based on the Jason-2/Jason- 1 tandem and the same map computed with only Jason-2. Black and purple lines highlight satellite tracks. The tandem was able to observe a $80 \mathrm{~cm}$ eddy that was barely detected by Jason-2. More generally, mesoscale features are better resolved.

Statistically, the SLA variance observed by the tandem (see figure 9) is not only much larger than the variance observed with a single sensor, but it also gives a coherent and homogeneous description of the Gulf Stream, whereas energy is visible only as peaks along Jason-2 tracks and crossovers for the single satellite configuration. The same applies for the eddy kinetic energy (EKE) which is $45 \%$ higher when an interleaved Jason is added in near real time multi-satellite mapping. A significant change from the TOPEX-based interleaved tandem is that the first data merging both Jasons were produced only two weeks after the interleaved tandem creation, making such improvements available to operational applications [e.g. Bell et al, 2009] with unprecedented quickness.

The Jason-2/Jason-1 interleaved orbit configuration also produced more subtle sampling improvements in Near Real Time: the observation is more coherent throughout time. Figure 10 shows the mean eddy kinetic energy of a $500 \mathrm{~km}$ wide area in the Gulf Stream for Jason-2 maps (black) and for the interleaved tandem (light grey). For the former, the curve is clearly not continuous with offsets on a 10-day pattern associated with near real time processing: when a specific grid point is mapped, information from the past only are available, and the objective analysis is not an ocean model so it cannot predict the local evolution of the EKE. Every 10 days, a new track from Jason-2 brings new information on the SSH and thus a discontinuity in the time series. The very same effect was visible on the TP/Jason-1 NRT maps and even amplified by the ñparallelò configuration (two samples every 10-days, then nothing in between). Conversely the Jason-2/Jason-1 and the 5-day offset minimizes this near real time artefact as samples are provided more frequently, resulting in a more coherent 
NRT multi-sensor map. This effect is also visible on animations and movies from the NRT MSLA: time series based on Jason-1 alone exhibit occurrences of eddies popping out of nowhere (or disappearing entirely) on areas the satellite overflies, whereas tandem maps are more coherent throughout time.

\subsubsection{Degrees of Freedom of Signal and Jason-2}

To perform a theoretical estimate of the impact of additional observations in a mapping or assimilating system, the traditional approach is to perform Observing System Experiments (OSEs) or impact studies as in [Le Traon and Dibarboure, 2002]. An alternative is now used in the atmospheric [Fisher, 2003; Chapnik, 2006] and ocean [Oke et al, 2009] modeling communities: the Degrees of Freedom of Signal (hereafter DFS). The DFS provide a measure of the gain in information brought by the observations. In a linear framework, DFS are deýned as the trace of the HK matrix where $\mathrm{K}$ refers to the assimilation Kalman gain matrix. The objective analysis is a Gauss-Markov estimator, and it provides a direct access to the HK matrix as it is explicitly computed along with the error covariance matrix or formal mapping error [Bretherton et al, 1976]. The DFS are computed on each HK matrix, meaning each grid point in the case of a suboptimal objective analysis.

It is thus possible to use this metric to access the local mapping gain in information provided by each dataset. Partial Degrees of Freedom of Signal are associated with a particular subset (e.g. a given satellite) of observations and computed from the partial trace of the HK matrix, taking only elements associated with the subset to be analyzed. The partial DFS associated with the subset $i$ is written DFS(i). Partial DFS can be computed only when there is no correlation between the errors of each dataset, which is a basic assumption made in DUACSôobjective analysis. It is then possible to derive two metrics from the partial DFS:

- $\quad \mathrm{C}(\mathrm{i})$ the fraction of the overall information coming from a given satellite, i.e the sensorspecific contribution to the multi-satellite map: if $\mathrm{C}(\mathrm{i})$ is 0.5 , half the local map content comes from sensor i

- $E(i)$ the fraction of the information from a given satellite actually exploited by the objective analysis, i.e. the amount of information not lost to duplicate data and measurement error: if $E(i)$ is 0.5 , half the information from satellite $i$ is lost to duplicates and measurement errors

The former is computed as DFS(i) / Sum ${ }^{i}$ (DFS(i)), and the latter as DFS(i) / N(i) where N(i) is the actual number of observations from dataset $\mathrm{i}$. In a mapping context, the DFS is dictated by the OI correlation scales, by the space/time distribution of observations (e.g. redundant datasets have $\mathrm{E}$ (i) equal to $50 \%$, and isolated datasets have a $\mathrm{E}$ (i) close to $100 \%$ ) and by the error covariance matrix given a priori to the OI : error-free datasets would get a $100 \%$ value for $\mathrm{E}(\mathrm{i})$ and $\mathrm{C}$ (i) if merged with datasets with large error bars.

The DFS analysis provides precious insights on the sampling contribution of each satellite, dynamically and from within the constellation (as opposed to OSE where the estimation is an external comparison: with/without). Figure 11 shows a map of $\mathrm{C}(\mathrm{i})$, i.e. the fraction of the multi-satellite map coming from ENVISAT (left) or Jason-2 (right) and zooms in the North Atlantic (bottom row). These maps are derived from the DFS analysis of an actual Jason2+Jason-1+ENVISAT sea level anomaly map computed in NRT. In average, each satellite provides $30 \%$ to $40 \%$ of the information, except at higher latitudes: in the $60-66^{\circ}$ latitude band, Jason-2 $\hat{\Phi}$ track geometry and ice-resilient tracking provide much more along-track SLA, making C(ENVISAT) drop to less than $20 \%$, and above $66^{\circ} \mathrm{C}(\mathrm{ENVISAT})$ is naturally $100 \%$ as it is the only satellite providing data to the Ol.

The satellite tracks of the last 10 days of NRT data are superimposed as black lines in the North Atlantic zooms. The DFS increases when along-track data are located nearby in space 
and time as visible on the bottom right map of Figure 11: the contribution from Jason-2 increases to $45 \%$ or $60 \%$ along the most recent tracks, and it decreases to $25 \%$ away from the satellite track (crossover diamonds).

The DFS is dependent on the error budget given to observations in the mapping or assimilation system, and of the covariance of the oceanic variability: Table 1 shows averages of the DFS analysis of Jason-2+ENVISAT maps for various error parameters. The top panels are averages over zones where the oceanic variability is higher than $15 \mathrm{~cm}$. When the observations are assumed to be error-free ( $1 \mathrm{~mm}$ noise and orbit error assumption in the $\mathrm{Ol}$ ), the fraction $\mathrm{E}(\mathrm{i})$ of the satellite information actually used by the $\mathrm{OI}$ is $81 \%$ to $96 \%$ (right panels). However for standard error patterns from [Le Traon et al, 2003], the coefficient $E(i)$ decreases to $45 \%$ : two measurements with errors are needed to reconstruct the equivalent of a perfect observation in the Ol. When the error is increased by $2 \mathrm{~cm}$ (either as noise variance or along-track correlated error), E decreases and the usable fraction of ENVISAT is only $37 \%$. In areas where the oceanic variability is lower than $10 \mathrm{~cm}$ (bottom panels), the OI is more sensitive to errors and the usable fraction of ENVISAT decreases to $27 \%$. The sensitivity is also different: in zones of intense mesoscale activity, correlated errors have a stronger impact on ENVISAT usability (37\% when $2 \mathrm{~cm}$ are added to the correlated error budget, vs $42 \%$ when $2 \mathrm{~cm}$ are added to the decorrelated error budget), whereas uncorrelated errors have more impact elsewhere ( $29 \%$ vs $27 \%$ respectively).

The fraction of the multi-satellite map coming from each mission $\mathrm{C}(\mathrm{i})$ is also affected when the ENVISAT error budget increases. When error levels are roughly equivalent at global scale, left panels of Table 1 exhibits respective $C$ values almost equal to $50 \%$. However when $2 \mathrm{~cm}$ error level are added to ENVISAT mapping parameters, its relative contribution to the two-satellite map globally decreases to $42 \%$. Again, the impacts of correlated and uncorrelated errors are different in intense mesoscale areas and in zones of weak oceanic variability.

Arguably the most interesting result that can be derived from the DFS analysis is in table 2 . When Jason-1 is added to Jason-2+ENVISAT in the mapping process, the multi-satellite map is built from all satellites almost evenly. Furthermore, although a third satellite is added, the fraction of information actually used from each satellite barely decreases on Jason-2 and ENVISAT (from $41 \%$ to $39 \%$ ). Adding the Jason-1 interleaved provides more data used by the OI in addition to Jason-2 and ENVISAT. The level of sampling duplicates (oversampling) between the third satellite and the non-coordinated ones is only a few percents. The DFS analysis confirms that DUACSôNRT mapping is actually exploiting the full extent of the third satellite [Pascual et al, 2008] and that its contribution is not competing with the first two.

These results are in line with [Le Traon and Dibarboure, 1999] as they both derive from the analysis of the OI gain matrix, but the DFS is significantly more efficient because it provides an on-the-fly estimate of the contribution of each satellite to the altimeter constellation, and from within this constellation. DFS may provide a baseline for operational indicators in DUACS from 2011 onwards.

\subsection{DT-2010 Reprocessing}

Every few years, DUACS performs a global reprocessing on all missions from

Figure 1, taking into account recent improvements and new recommendations from the altimetry community, or new L2 GDR releases from the Agencies as well as alternate ancillary datasets from other projects. Such a reprocessing is not trivial as it involves an update of the full climate data record with 60 years-worth of cumulated altimetry from 8 satellites (or 10 sensors) and thousands of multi-mission maps. With the improvements from Jason-2 standards (GDR version C), DUACS has carried out an extensive reprocessing in 2009. It led to the DT-2010 product generation, released on AVISO in Spring 2010. 
Major changes from the previous generation (DT-2007, released on AVISO in early 2008) include the implementation of GDR-C standards, either from actual reprocessing (Jason-1) or operational products (Jason-2) or from equivalent updates applied directly on the DUACS database (e.g. GOT4v7 tidal model, High Resolution DAC/MOG2D correction...). New orbit solutions were used (from CNES GDR-C for ENVISAT, from GSFC for T/P and GFO) and various corrections were updated: new SSB solutions on T/P, ENVISAT and GFO (from Tran and Labroue, computed specifically for the DUACS reprocessing with GDR-C standards and the latest orbit solutions), minimization of brightness temperature drifts on ERS and computation of a new wet troposphere correction with neural network (derived from Expert Support Laboratory activities carried out by CLS for ESA), new Mean Dynamic Topography [Rio, 2009] for a sharper description of absolute sea surface topography features. These updates are fully documented in [AVISO, 2010b]. They resulted in a significant error variance reduction shown in figure 3 .

New Mean Profiles were computed from the GDR-C database update with a focus on interannual variability, coastal and high latitude coverage. Previous releases of DUACS MPS were conservative in the trade-off between coverage and the risk of quality loss associated with coastal zones or ice coverage. The DT-2010 provides an extended coverage of multimission maps at high latitudes (Figure 12 in the Southern Hemisphere), as well as alongtrack products in various coastal zones (figure 13) in the Black Sea). The improved coverage comes from better editing processes (e.g. thresholds adjusted, cross-comparison vs. local dynamics) [AVISO, 2010a], and slightly relaxed confidence intervals on the MPs : in DT-2007 the time average was considered invalid if it was computed on less than $60 \%$ of the dataset lengths, whereas this criterion is now relaxed at higher latitude and complemented with cross-validation algorithms. Extensive validation of both MP and along-track SLA were carried out to ensure that the extended coverage was still on par with QC procedures.

DUACS processing were also adjusted with minor changes in the mapping (e.g.: size of suboptimal interpolation window increased by $33 \%$ ), editing and cross-calibration processes (e.g.: adjustment of the error prescribed for modern missions). Moreover, climate applications were a priority for this reprocessing, so the transition date and the crosscalibration between consecutive reference missions exploited the most recent findings from the CalVal and Mean Sea Level communities (e.g. global or regional biases between TP/Jason-1 and Jason-1/Jason-2 are better accounted for). This reprocessing tries to ensure that the global and regional mean sea level derived from multi-mission products are as coherent as possible with the regional Mean Sea Level derived from T/P and Jason-1 and Jason-2. The difference between the global sea level trend for DT-2007 and DT-2010 is 0.1 $\mathrm{mm} / \mathrm{year}$, and at basin scale the difference can be larger than $1 \mathrm{~mm} / \mathrm{year}$.

Thus in addition to new Jason-2 standards, this mission was used to extend the computation time span of Mean Profiles, and to better account for the transition between reference missions. Furthermore, Jason-2 is now used as the DT reference mission since 2008 whereas Jason-1 was used until March 2009 in NRT and in the previous DT release.

\section{Long term impact of having Jason-2 in DUACS}

\subsection{Reference mission continuity}

Unarguably the most important contribution of Jason-2 in DUACS is that it consolidates the so-called reference time series needed to build a robust multi-mission climate record. The reference series is important for mesoscale applications but it becomes critical for climateoriented applications using altimetry maps. The reference mission not only reduces 
geographically correlated errors (trackiness artefacts on maps, [Le Traon et Ogor, 1998]) but also better describes large interannual features and the regional mean sea level trend.

Figure 14 shows the difference between the Jason-1 sea level trend from [Ablain et al, 2010] and the exact same computation carried out on GFO before cross-calibration (GDR-C corrections, and recent GSFC orbits are used, as per section 0 ). The differences are locally as large $10 \mathrm{~mm} /$ year with orbit-shaped and basin-wide artefacts. In terms of global MSL trend, the difference ranges from $0.9 \mathrm{~mm} /$ year when the radiometers are used for the wet troposphere correction to $1.1 \mathrm{~mm} /$ year when the ECMWF is used on both missions. After the cross-calibration these artefacts are minimized and the difference is less than $1 \mathrm{~mm} / \mathrm{year}$ at local scale and $0.3 \mathrm{~mm} /$ year at global scale.

\subsection{New cross-calibration algorithm with multiple references}

Jason-2 is to this day the best mission equipped for Precise Orbit Determination (POD) in

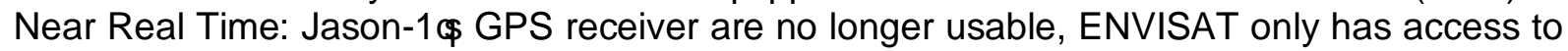
Doris and laser reflectors. However, in contrast to the T/P and ERS era, the difference between the POD accuracy on the reference mission and on other satellites is no longer a factor of 5 to 10 in near real time. The basic assumption of DUACSôOER process is that one mission holds the absolute truth and that other missions should be adjusted onto the reference mission. This assumption was relevant in the nineties, but it is arguable in 2010 . Future missions such as AltiKa, or Sentinel3 will consolidate this statement as their specifications are equal or stricter than ENVISAT $\hat{\mathbf{\Phi}}$.

Based on this observation, a new OER scheme was developed exploiting multiple references at once (primarily for Jason-2+Jason-1 NRT and MOE orbit). This two step process performs a unique global minimization on all p̃preciseòmissions, and then a standard reference-based adjustment of the less precise missions. It is a generalization of the [Le Traon et Ogor 1998] OER scheme. In a two-satellite context, the algorithms is looking for spline functions S and Sô (OER correction for each reference satellite) that minimizes the cost function from the following equation:

$$
\begin{aligned}
\mathrm{F}(\mathrm{C}) & =\sum_{i=1}^{M} w_{i}^{2}\left[S\left(t_{i 1}\right)-S\left(t_{i 2}\right)-y_{i}\right]^{2} \\
& +\sum_{j=1}^{P} w_{j}^{2}\left[S^{\prime \prime}\left(t^{\prime}{ }_{j 1}\right)-S\left(t_{j 2}\right)-d_{j}\right]^{2} \\
& +\sum_{k=1}^{Q} w_{k}^{2}\left[S^{\prime}\left(t^{\prime}{ }_{k 1}\right)-S^{\prime}\left(t^{\prime}{ }_{k 2}\right)-z_{k}\right]^{2} \\
& +\sum_{l=1}^{R} w_{l}^{2}\left[S\left(t_{l 1}\right)-\operatorname{Comb}(S L A)_{l}\right]^{2}+\sum_{p=1}^{T} w_{p}^{2}\left[S^{\prime}\left(t_{p 1}^{\prime}\right)-\operatorname{Comb}(S L A)_{p}\right]^{2}
\end{aligned}
$$

Where $y$ and $z$ are the value of mono-mission crossover differences, and $d$ the value of multimission crossover differences, $M, P$, and $Q$ are crossover indexes, and $R, T$ are arbitrary points used to provide an absolute constraint to $S$ and Sô The constraint is performed by minimizing the difference to $\operatorname{Comb}(S L A)$, which is defined as Comb(SLA) $=S S H(I)$ i $M S S(I)$ ï $\operatorname{MSLA}(I)$, where $S S H(I)$ is the altimeter measurement on location I from the R or T ensemble, MSS(I) the mean profile or gridded mss, and MSLA $(I)$ is a large scale sea level anomaly first guess. Comb(SLA), is in essence the sum of small scale signals not resolved by the constellation. Lastly, $w_{i}$ are the weights associated with each type of minimization, which are defined from the confidence interval given to each mission (error observed by $\mathrm{Cal} / \mathrm{Val}$ on non-calibrated crossovers, [AVISO, 2010a]). The minimization of this cost function is carried 
out with simple least squares and bicubic spline functions similar to [Le Traon and Ogor, 1998]. The problem can be generalized with three or more precise missions by adding a Sò OER function, new subsets of crossover minimizations and absolute calibrations on Comb(SLA).

This process was applied to one year of near real time data from Jason-1 and ENVISAT, and the same experiment was applied on a shorter Jason-2 window with similar results.

Figure 2 shows maps of crossover differences before (left column) and after (middle column) the multi-reference OER is applied. Geographically correlated discrepancies ranging from 1 to $5 \mathrm{~cm}$ are reduced to centimetric coherency, both on mono-mission crossovers of each satellite, and on the differences between Jason-1 and ENVISAT.

The right column in figure 2 shows the temporal evolution of the crossover difference standard deviation over the 12 month period. The black curve is before orbit error reduction, the red curve is after classical orbit error reduction, and the blue curve is after multi-reference orbit error reduction. For ENVISAT, the OER process is basically equivalent to what was done one by the historical mono-reference scheme, and for Jason-1 the new process provides a slightly better variance reduction for two reasons: 1/ the new OER is not limited to

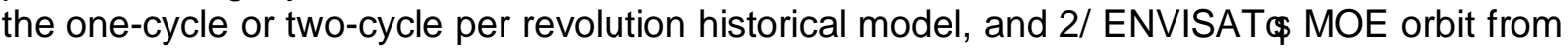
CNES is sufficiently accurate in NRT to help improve Jason-1 in the global minimization. Sensibility studies were carried to ensure that these results are resilient to the changes in the MSLA first guess (absolute calibration of the OER), and to minor errors in weighting parameters.

Once more experiments are performed on degraded NRT configurations (data gaps, incremental computation of the first guessé ) this processing will replace the traditional OER

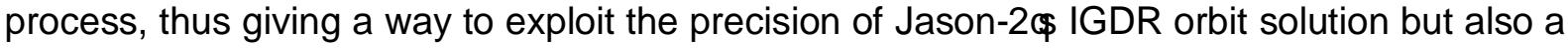

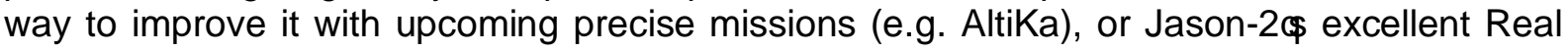
Time orbit determination.

\section{Conclusions}

Adding a new mission into the multi-satellite system DUACS has a wide range of impacts, from short term product quality improvements to long term processing changes. This is particularly true for the so-called reference mission as it controls a large fraction the multimission basin-wide interannual signals, and MSL trend. Therefore it focuses the effort of CalVal, cross-calibration algorithms and QC process. For the first time in more than thirteen years of DUACS existence, Jason-2 demonstrated that it is technically possible to exploit a new reference mission for operational L3/L4 multi-mission products less than one month after launch.

Adding Jason-2 and the interleaved tandem to DUACS not only restored the 3-satellite configuration required for near real time monitoring of mesoscale and ocean circulation, but it also highlighted the benefits of the new tandem configuration, primarily for large and rapid signals (e.g. storm surge), but also for near real time multi-mission SLA maps. The improvements associated with the Jason-2/Jason-1 tandem were observed in near real time in a consistent way with past papers on the first tandem. New GDR standards and processing were also developed with Jason-2, which in turn allowed DUACS to reprocess all altimetry sensors up until the first year of Jason-2. Improved data handling at high latitudes and close to the coasts have extended data coverage and quality. The Jason-2 integration also triggered the development of new algorithms such as the multi-reference orbit reduction scheme, and new theoretical metrics such as the DFS applied to the multi-satellite objective analysis. 
Therefore, Jason-2 is not ñustòa follow-on mission whose primary objective is to secure the long-term climate data record. It is also contributing to increasing the quality of the altimetric constellation and multi-mission products. This contribution was observed on novel theoretical estimators, on new processing techniques, on reprocessing campaigns exploiting this new dataset and the associated standards, and on actual products, in Near Real Time and in Delayed Time.

\section{Acknowledgements}

The DUACS system is a joint CLS/CNES system maintained and operated with support from the SALP project from CNES. It benefits from co-funding from the MyOcean FP7 project. (O/I)GDR input data are provided by CNES, ESA, Eumetsat, NASA and NOAA. DUACS benefits from technical contributions and altimetry expertise developed and sustained in the framework of CalVal, cross-calibration and other altimetry-related activities carried out for CNES (SALP project and PISTACH initiative), and ESA (Expert Support Laboratory contract, WOOPI and REAPER projects, Climate Change Initiative). The authors would like to thank Brian Beckley and the GSFC group for kindly providing consistently reprocessed T/P and GFO orbit solutions which were very helpful to the DT-2010 reprocessing.

\section{References}

- Ablain et al, (2009): Annual report (2009) of tide gauges and altimeter comparisons for $\mathrm{T} / \mathrm{P}$, Jason-1/2 and Envisat

http://www.aviso.oceanobs.com/fileadmin/documents/calval/validation_report/insitu/annu al_report_insitu_2008.pdf.

- Ablain. M, S.Philipps, N.Picot, E.Bronner (2010): Jason-2 global statistical assessment and cross-calibration with Jason-1 (Marine Geodesy, Jason-2 special edition, volume 1, in press)

- Ablain, M., Valladeau, G., Lombard, A., Bronner, E. \& Femenias, P. (2010). "Quality assessment of in-situ and altimeter measurements through SSH comparisons" in Proceedings of OceanObs'09: Sustained Ocean Observations and Information for Society (Annex), Venice, Italy, 21-25 September 2009, Hall, J., Harrison, D.E. \& Stammer, D., Eds., ESA Publication WPP-306.

- AVISO (2010a): Cal/Val and cross-calibration annual reports http://www.aviso.oceanobs.com/es/calval/systematic-calval/index.html

- AVISO (2010b): SSALTO/DUACS User Handbook : (M)SLA and (M)ADT Near-Real Time and Delayed Time Products, CNES document SALP-MU-P-EA-21065-CLS, latest version available on AVISO website: http://www.aviso.oceanobs.com/en/data/tools/avisouser-handbooks/index.html

- AVISO (2010c): SSALTO/DUACS release notes http://www.aviso.oceanobs.com/en/data/productinformation/duacs/presentation/updates/index.html

- AVISO (2010d): Examples of practical DUACS applications http://www.aviso.oceanobs.com/en/data/product-information/duacs/ssaltoduacsusers/index.html

- AVISO (2010e): Operational News http://www.aviso.oceanobs.com/no_cache/en/data/operational-news/index.html

- Balmaseda, Magdalena A., Arthur Vidard, and David L. T. Anderson (2008), The ECMWF Ocean Analysis System: ORA-S3, Mon Weather Rev, 136(8), 3018 
- Bell, MJ, Lefebvre, M., Le Traon, P.Y., N.Smith and K. Wilmer-Becker, K (2009): The Global Ocean Data Assimilation Experiment. Oceanography Vol.22, No.3, 14-21.

- Bretherton, F. P., Davis, R. E., and Fandry, C. B., (1976): A technique for objective analysis and design of oceanographic experiment applied to MODE-73. Deep-Sea Research, 23:559-582

- Cardinali, C., Pezzuli, S., and Andersson, E. (2004): Influence matrix diagnostic of a data assimilation system, Q. J. Roy. Meteorol. Soc., 130 , $2767 i ̈$ 2786, 2004.

- Chapnik, B., Desroziers, G., Rabier, F., and Talagrand, O., (2006): Diagnosis and tuning of observational error statistics in a quasi operational data assimilation setting, Q. J. Roy. Meteorol. Soc., 132, 543ï 565, 2006.

- Chelton et al, (2007): Global observations of large oceanic eddies. Geophys. Res. Letters, 34:L15606, 2007.

- Chelton, D. B., M. G. Schlax, and R. M Samelson, (2010): Global observations of nonlinear mesoscale eddies. Prog. Oceanogr., (submitted)

- Cipollini, P., P.G. Challenor, and S. Colombo (2006): A method for tracking individual planetary waves in remotely sensed data, IEEE Trans Geosci Remote Sensing, 44(1), 159

- Dibarboure et al, 2008, Overview of 3 phasing options for a Jason-1 / Jason-2 tandem, Proceedings of OSTST Meeting (November 2008)

- Dorandeu, J., M. Ablain, P-Y. Le Traon, (2003): Reducing Cross-Track Geoid Gradient Errors around TOPEX/Poseidon and Jason-1 Nominal Tracks: Application to Calculation of Sea Level Anomalies. Journal of Atmospheric and Oceanic Technology, 20, 18261838

- Dorandeu.J, M. Ablain; Y. Faugere; F. Mertz; B. Soussi; and P. Vincent (2004): Jason-1 global statistical evaluation and performance assessment: Calibration and crosscalibration results, Marine Geodesy, 27, 2004 , 345-372

- Ducet, N., P.Y. Le Traon and G. Reverdin, (2000): Global high resolution mapping of ocean circulation from the combination of TOPEX/POSEIDON and ERS-1/2. Journal of Geophysical Research (Oceans), 105, C8, 19,477-19,498.

- Ducet, N. and P.-Y. Le Traon, (2001): A comparison of surface eddy kinetic energy and Reynold stresses in the Gulf Stream and the Kuroshio Current systems from merged TOPEX/Poseidon and ERS-1/2 altimetric data. J. Geophys. Res., 106, 16603-16622.

- Faugere.Y, J Dorandeu, F Lefevre, N Picot, P Femenias (2006), Envisat Ocean Altimetry Performance Assessment and Cross-calibration, Sensors 2006, 6, 100-130 sensors ISSN 1424-8220

- Fisher, M. (2003): Estimation of entropy reduction and degrees of freedom for signal for large variational analysis systems, Technical Memo., 397, ECMWF, Reading, UK.

- Fu, Lee-Lueng (2006): Pathways of eddies in the South Atlantic Ocean revealed from satellite altimeter observations, Geophys Res Lett, 33, L14610

- Fu, Lee-Lueng (2009): Pattern and velocity of propagation of the global ocean eddy variability, J. Geophys. Res., 114, C11017, doi:10.1029/2009JC005349

- Haines, B., M.Armatys, Y.Bar-Sever, W.Bertiger, S.Desai, A.Dorsey, C.Lane, and J.Weiss (2010): One-centimeter orbits in near-real time : the GPS experience on OSTM/JASON-2, AAS George H Boorn Symposium, Boulder, Colorado, May 2010 : http://trs-new.jpl.nasa.gov/dspace/handle/2014/41634

- Greenslade, D., D.Chelton, M.Schlax, (1997): The Midlatitude Resolution Capability of Sea Level Fields Constructed from Single and Multiple Satellite Altimeter Datasets. J. Atmos. Oceanic Technol., 14, 849ï 870.

- Jacobs, G., C.Barron, R.Rhodes (2001): Mesoscale characteristics, Journal of Geophysical Research, VOL. 106, NO. C9, PP. 19,581-19,595, 2001 
- Jayles, C., J.P. Chauveau, and F. Rozo, (2010): DORIS/Jason-2: Better than $10 \mathrm{~cm}$ onboard orbits available for Near-Real-Time Altimetry, Advances in Space Research 2010, vol 46-12, doi:10.1016/j.asr.2010.04.030

- Johannessen, J.A., P.-Y. Le Traon, I. Robinson, K. Nittis, M. J. Bell, N. Pinardi and P. Bahurel, (2006): Marine Environment and Security for the European Area Toward Operational Oceanography, BAMS, 1081-1090.

- Johnson, Eric S., Fabrice Bonjean, Gary S. E. Lagerloef, John T. Gunn, and Gary T. Mitchum (2007), Validation and Error Analysis of OSCAR Sea Surface Currents, J Atmos Ocean Technol, 24(4), 688

- Le Traon, P.Y. and F. Ogor, (1998): ERS-1/2 orbit improvement using TOPEX/POSEIDON : The $2 \mathrm{~cm}$ challenge. Journal of Geophysical Research (Oceans), 103, 8045-8057.

- Le Traon, P.Y., Nadal F. and N. Ducet, (1998): An improved Mapping Method of Multisatellite Altimeter Data. Journal of Atmospheric and Oceanic Technology, 15, $522-$ 533.

- Le Traon, P. Y., and G. Dibarboure, (2002): Velocity Mapping Capabilities of Present and Future Altimeter Missions: The Role of High-Frequency Signals. J. Atmos. Oceanic Technol., 19, 2077ï 2087.

- Le Traon, P.Y., Faugère Y., Hernandez F., Dorandeu J., Mertz F. and M. Ablain, (2003). Can we merge GEOSAT Follow-On with TOPEX/POSEIDON and ERS-2 for an improved description of the ocean circulation ? Journal of Atmospheric and Oceanic Technology, 20, 889-895.

- Le Traon, P.Y. and G. Dibarboure, (2004). Illustration of the contribution of the tandem mission to mesoscale studies. Marine Geodesy, 27, 3-13.

- Le Traon P.Y, G.Larnicol, S.Guinehut, S.Pouliquen, A.Bentamy, D.Roemmich, C.Donlon, H.Roquet, G.Jacobs, D.Griffin, F.Bonjean, N.Hoepffner, L.A.Breivik (2009). Data assembly and processing for operational oceanography 10 years of achievements. Oceanography, 22(3), 56-69.

- Mertz.F , JF.Piolle, P. Féménias, E. Bronner, (2010): ERS-2 Altimeter Data Quality

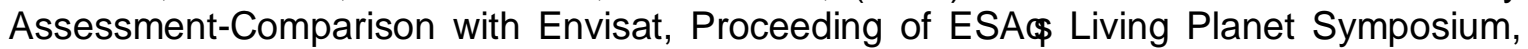
2010

- Morrow, R., M.L. Ward, S. Pasquet \& A. McC.Hogg (2010). Eddy response to Southern Ocean climate modes. J. Geophys. Res., In Press.

- d'Ovidio, F., J. Isern-Fontanet, C. López, E. García-Ladona, E. Hernández-García (2009), Comparison between Eulerian diagnostics and the finite-size Lyapunov exponent computed from altimetry in the Algerian Basin, Deep Sea Res. I, 56, 15-31.

- Oke Peter R., Balmaseda Magdalena A., Benkiran Mounir, Cummings James A., Dombrowsky Eric, Fujii Yosuke, Guinehut Stéphanie, Larnicol Gilles, Le Traon PierreYves, Martin Matthew J. (2009). Observing system evaluations using GODAE systems. Oceanography, 22(3), 144-153.

- Ollivier.A; Y.Faugere, N.Picot, P.Femenias, (2010): Envisat ocean altimetry performance

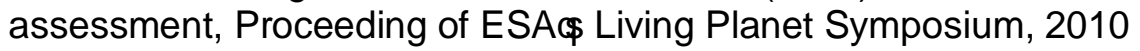

- Pascual, A., Y. Faugère, G. Larnicol, P.-Y. Le Traon (2006). "Improved description of the ocean mesoscale variability by combining four satellites altimeters." Geophys Reseach Letters 33(doi:10.1029/2005GL024633).

- Pascual A., C. Boone, G Larnicol, P.Y. Le Traon (2008) On the quality of real time altimeter gridded fields: comparison with in situ data, Journal of Atmospheric and Oceanic Technology, vol. 26, issue 3, p. 556.

- Prandi, P., A. Cazenave, and M. Becker (2009): Is coastal mean sea level rising faster than the global mean? A comparison between tide gauges and satellite altimetry over 1993ï 2007, Geophys. Res. Lett., 36, L05602, doi:10.1029/2008GL036564 
- Quu, Bo, and Shuiming Chen (2010), Interannual Variability of the North Pacific Subtropical Countercurrent and Its Associated Mesoscale Eddy Field, J Phys Oceanogr, 40(1), 213

- Rio, M.-H., P. Schaeffer, G. Moreaux, S. Bourgogne, J.-M. Lemoine, E. Bronner (2009): A new Mean Dynamic Topography computed over the global ocean from GRACE data, altimetry and in-situ measurements. Communication at the OceanoObs09 ESA symposium, 21-25 September 2009, Venice.

- Rio, M.-H. and F. Hernandez (2004). "A Mean Dynamic Topography computed over the world ocean from altimetry, in-situ measurements and a geoid model." Journal of Geophysical Research 109(C12).

- Rio, M-H., G.Larnicol (2010): The CNES/CLS Mean Dynamic Topography. Proceedings of the Ocean Surface Topography Science Team Meeting (2010). Map and documentation available on AVISO:

http://www.aviso.oceanobs.com/en/data/products/auxiliary-products/mdt/index.html

- Schaeffer, P., A.Ollivier; Y.Faugere; E.Bronner; N.Picot, (2010): The new CNES/CLS 2010 Mean Sea Surface. Proceedings of the ESA Living Planet Symposium 2010

- Stammer, D., (1997): Global Characteristics of Ocean Variability Estimated from Regional TOPEX/POSEIDON Altimeter Measurements. J. Phys. Oceanogr., 27, 1743111769.

- Stammer, D.; and J. Theiss (2004): Velocity Statistics Inferred from the TOPEX/Poseidon-Jason-1 Tandem Mission Data, Marine Geodesy, 1521-060X, Volume 27, Issue 3, 2004, Pages 551 ï 575

- Tai, C.K. (1988), Geosat Crossover Analysis in the Tropical Pacific 1. Constrained Sinusoidal Crossover Adjustment, J. Geophys. Res., 93(C9), 10,621ї 10,629, doi:10.1029/JC093iC09p10621.

- Tai, C.K, (2009): The Temporal Aliasing Formulas for the Tandem Mission of Jason-1 and TOPEX/Poseidon. Journal of Atmospheric and Oceanic Technology, 26, 352-367

- Willis, J. K. (2010): Can in situ floats and satellite altimeters detect long-term changes in Atlantic Ocean overturning?, Geophys. Res. Lett., 37, L06602, doi:10.1029/2010GL042372 


\section{Tables}

Table 1 : Averages from DFS analysis for four 2-satellite maps: perfect observations (obs error assumed to be $1 \mathrm{~mm}$ ), standard error budget, LWE error increased by $2 \mathrm{~cm}$, noise error increased by $2 \mathrm{~cm}$. The left panels show the fraction of the multi-satellite information coming from each mission or $\mathrm{C}($ sat $)=\mathrm{DFS}($ sat $) /$ Sum $\mathrm{i}(\mathrm{DFS}(\mathrm{i}))$, and the right panels show the fraction of mission-specific content actually exploited by the OI or E (sat)= DFS(sat)/N(sat). Top panels are for zones where the oceanic variability is higher than $15 \mathrm{~cm}$, and bottom panels for zones of oceanic variability lower than $10 \mathrm{~cm}$.

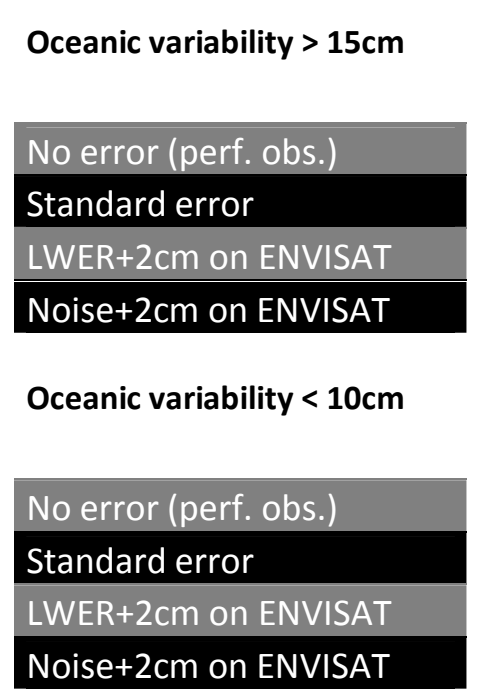

\begin{tabular}{|c|c|}
\hline \multicolumn{2}{|c|}{$\begin{array}{l}\text { Fraction of the map } \\
\text { coming from a satellite }\end{array}$} \\
\hline Jason2 & ENVISAT \\
\hline $53 \%$ & $47 \%$ \\
\hline $51 \%$ & $49 \%$ \\
\hline $55 \%$ & $45 \%$ \\
\hline $53 \%$ & $47 \%$ \\
\hline \multicolumn{2}{|c|}{$\begin{array}{l}\text { Fraction of the map } \\
\text { coming from a satellite }\end{array}$} \\
\hline Jason2 & ENVISAT \\
\hline $52 \%$ & $48 \%$ \\
\hline $51 \%$ & $49 \%$ \\
\hline $55 \%$ & $45 \%$ \\
\hline $58 \%$ & $42 \%$ \\
\hline
\end{tabular}

Fraction the satellite information actually used

\begin{tabular}{|r|r|}
\hline Jason2 & ENVISAT \\
\hline $96 \%$ & $95 \%$ \\
\hline $42 \%$ & $45 \%$ \\
\hline $42 \%$ & $37 \%$ \\
\hline $42 \%$ & $42 \%$ \\
\hline
\end{tabular}

Fraction the satellite information actually used Jason2 ENVISAT

\begin{tabular}{|r|r|}
\hline $82 \%$ & $81 \%$ \\
\hline $32 \%$ & $34 \%$ \\
\hline $32 \%$ & $29 \%$ \\
\hline $32 \%$ & $27 \%$ \\
\hline
\end{tabular}

Table 2: Averages from DFS analysis for two multi-mission maps: 3 satellites, and 2 satellites. The left panel shows the fraction of the multi-satellite information coming from each mission or $\mathrm{C}($ sat $)=\mathrm{DFS}($ sat $) / \mathrm{Sum} \mathrm{i}(\mathrm{DFS}(\mathrm{i}))$, and the right panel shows the fraction of mission-specific content actually exploited by the OI or E (sat)= DFS(sat)/N(sat).

Oceanic variability $>15 \mathrm{~cm}$

Jason1+Jason2+ENVISAT Jason2+ENVISAT
Fraction of the multi-satellite map coming from a satellite

\section{Jason2 ENVISAT Jason1}

\begin{tabular}{|r|r|r|}
\hline $36 \%$ & $32 \%$ & $32 \%$ \\
\hline $51 \%$ & $49 \%$ & $0 \%$ \\
\hline
\end{tabular}

Fraction the satellite information actually used

\begin{tabular}{|r|r|r|}
\hline Jason2 & ENVISAT & Jason1 \\
\hline $39 \%$ & $39 \%$ & $39 \%$ \\
\hline $41 \%$ & $44 \%$ & $0 \%$ \\
\hline
\end{tabular}




\section{Figures}

Figure 1: Timeline of satellite altimetry missions used (or expected) in the multi-sensor system DUACS

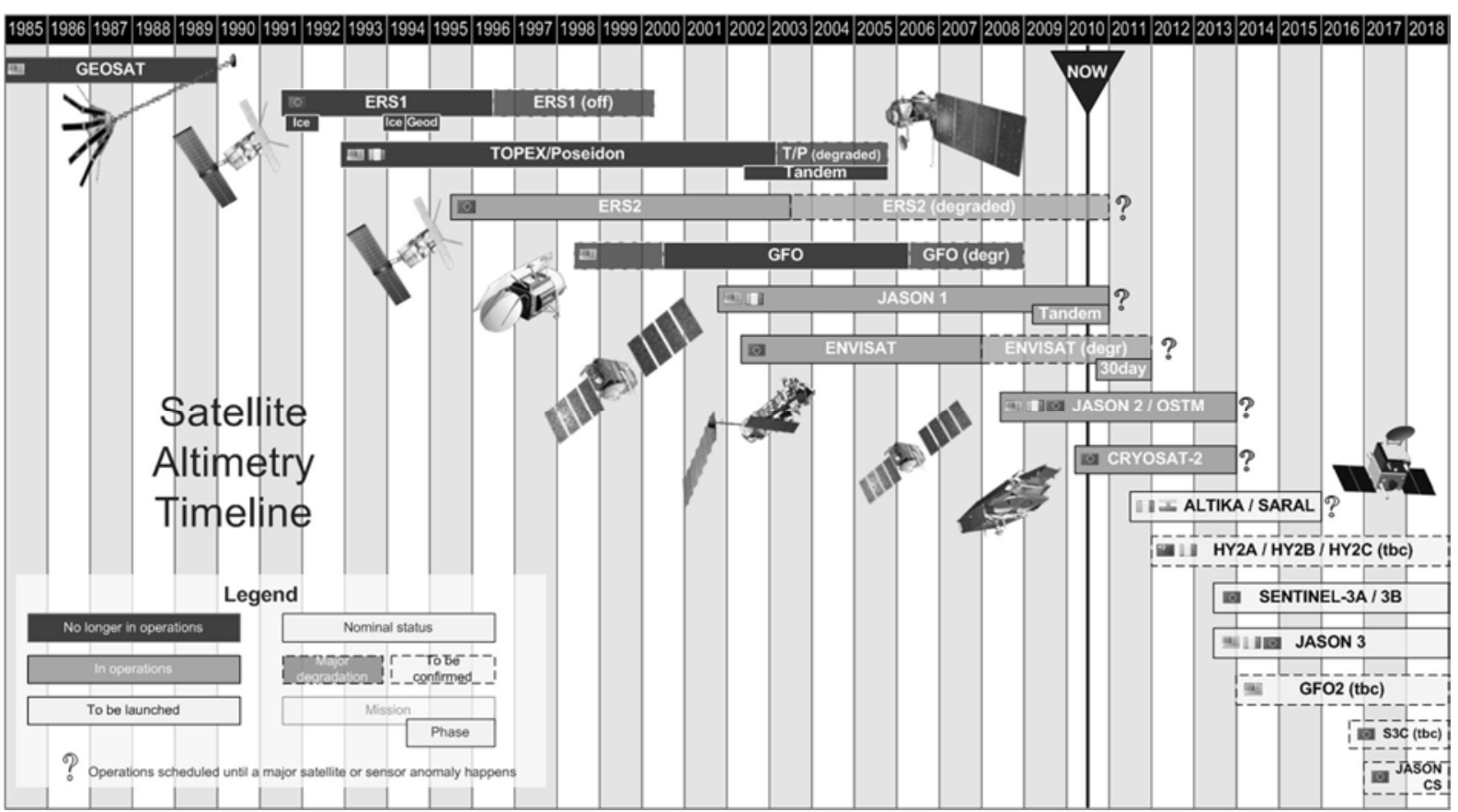


Figure 2 : Crossover differences before (left column) and after (middle column). Top row shows Jason-1xENVISAT crossovers, middle row is for ENVISATxENVISAT crossovers and bottom row is for Jason-1xJason-1 crossovers. The right column shows the temporal evolution of the crossover difference std over a 12 month period: black curve is before orbit error reduction, red curve is after classical one-reference orbit error reduction, and blue curve is after multi-reference orbit error reduction. Unit: $\mathrm{cm}$.

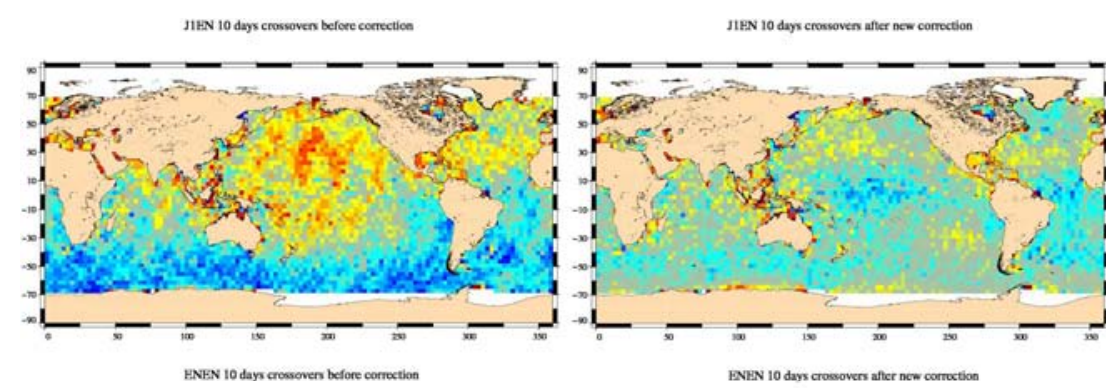

ENJ1 standard deviation at crossovers

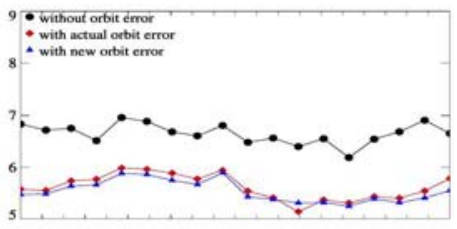

ENEN 10 days crossover before correction

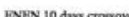

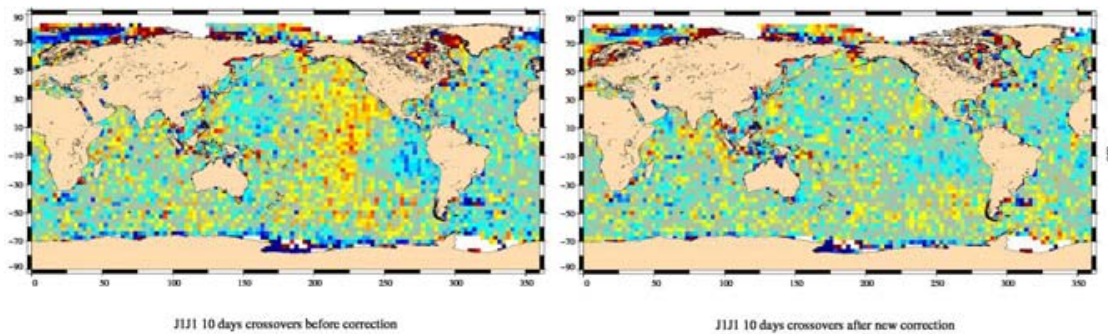

ENEN standard deviation at crossovers

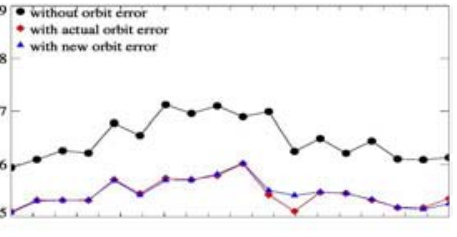

J1J1 standard deviation at crossovers

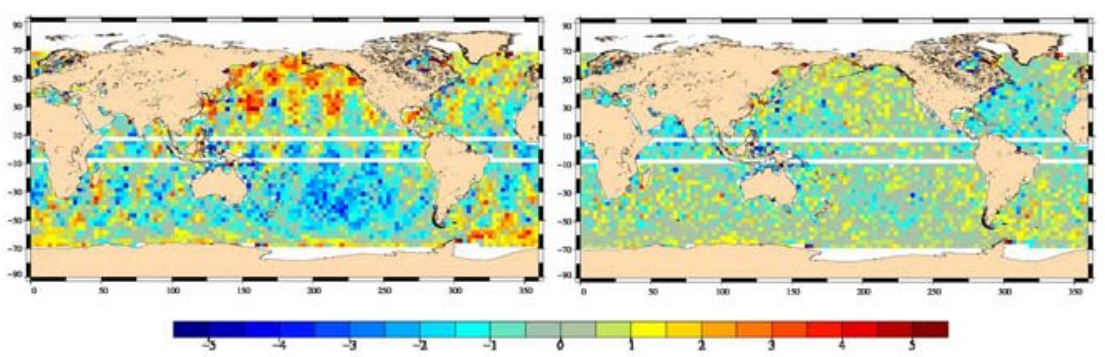

- withoul orbit érmor !
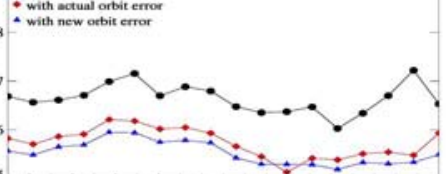

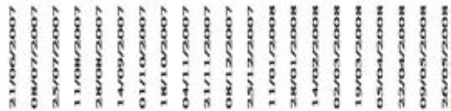


Figure 3 : Difference between the MSLA variance of DT-2010 maps and the MSLA variance of DT-2007 maps (January 1993, July 2009). Negative values show a variance decrease associated with GDR-C standards.

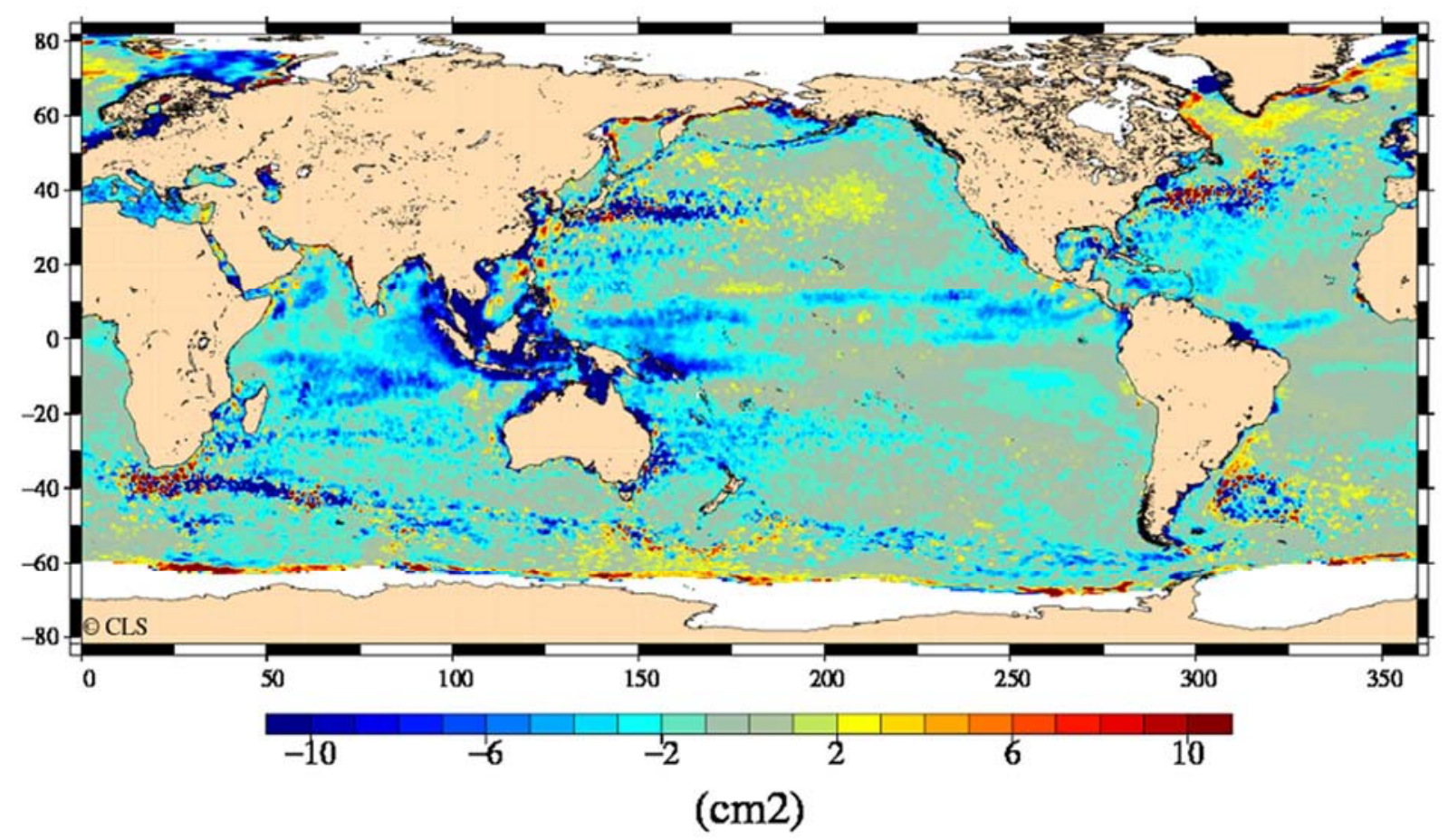

Figure 4 : Comparison of DUACSôalong-track Sea Level Anomaly (SLA) product with Tide Gauge data. Example of WOCE \#129 TG (Portland, Australia). Circles show the correlation between the local SLA time series (computed every $7 \mathrm{~km}$ along-track) and the tide gauge time series.

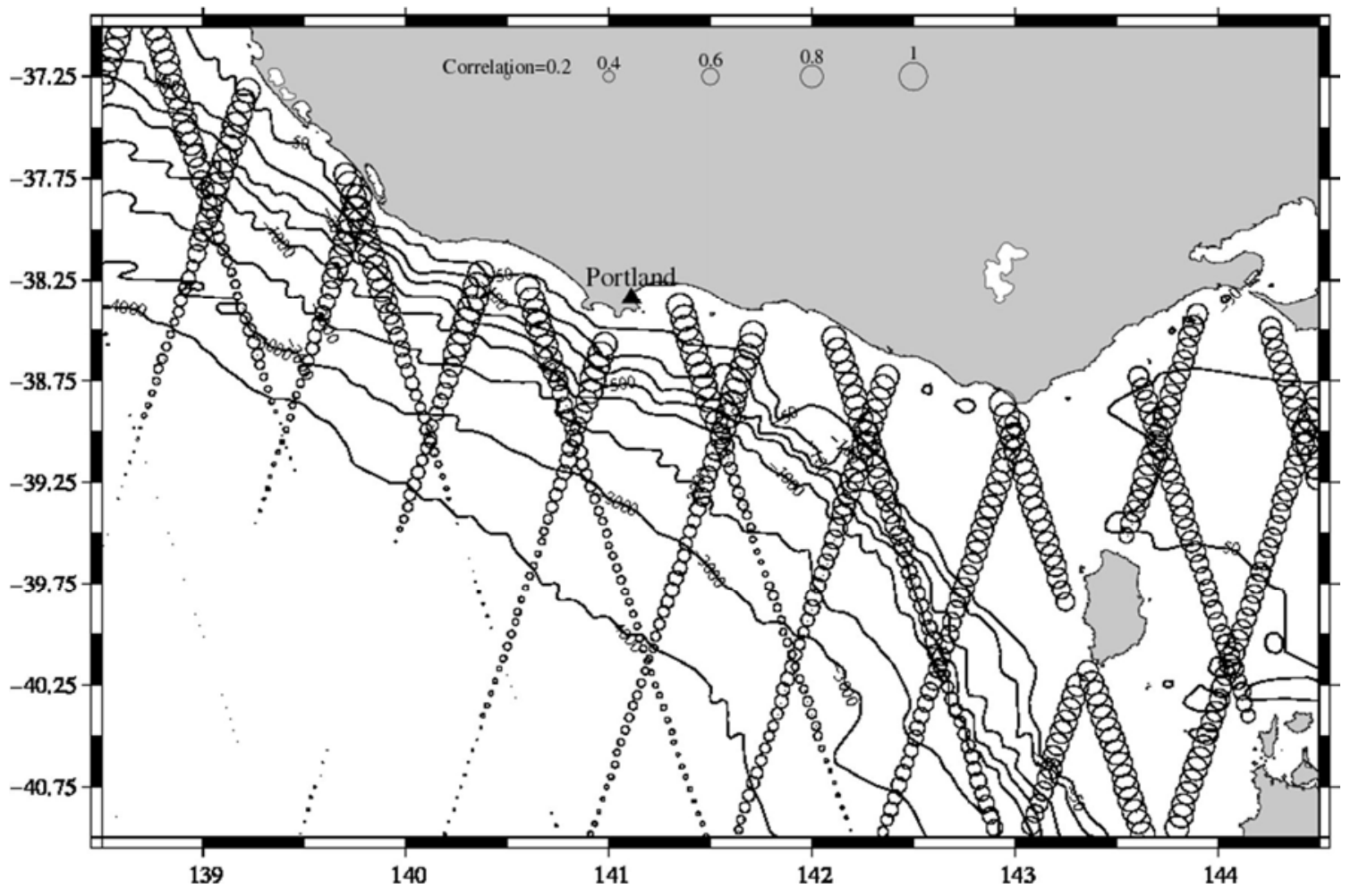


Figure 5 : Unit : $\mathrm{cm}$. Map of Absolute Dynamic Topography (MADT) from Jason-2+Jason$1+$ ENVISAT on 2010/07/01 (Gulf Stream). Black arrows show Lagrangian tracers derived from geostrophic velocities associated with the Sea Surface Height.

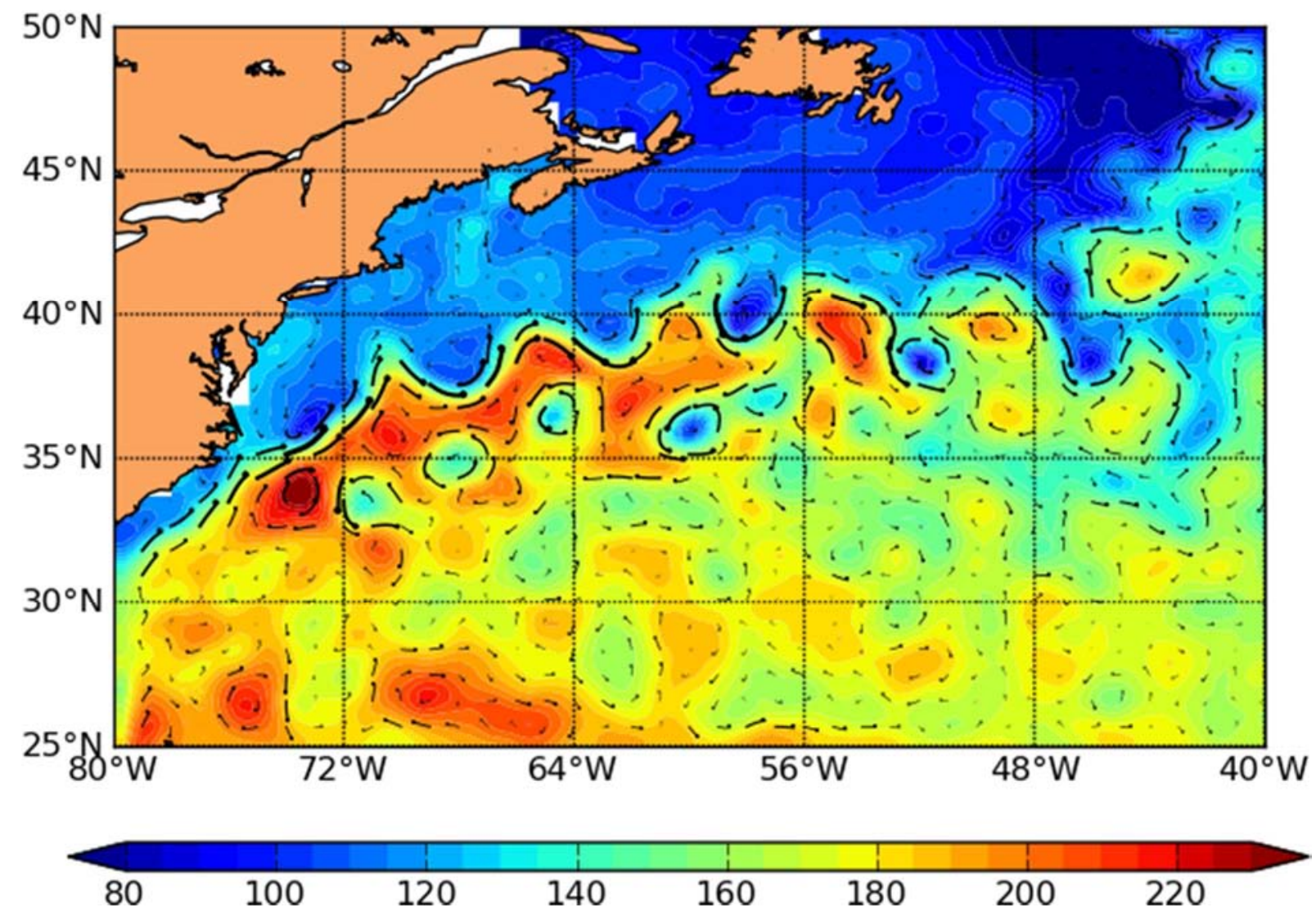

Figure 6 : First near real time contribution of Jason-2 to DUACS on 2008/08/16. Difference between the map of Sea Level Anomaly based on Jason-2 + ENVISAT + GFO and the same map based on ENVISAT + GFO.

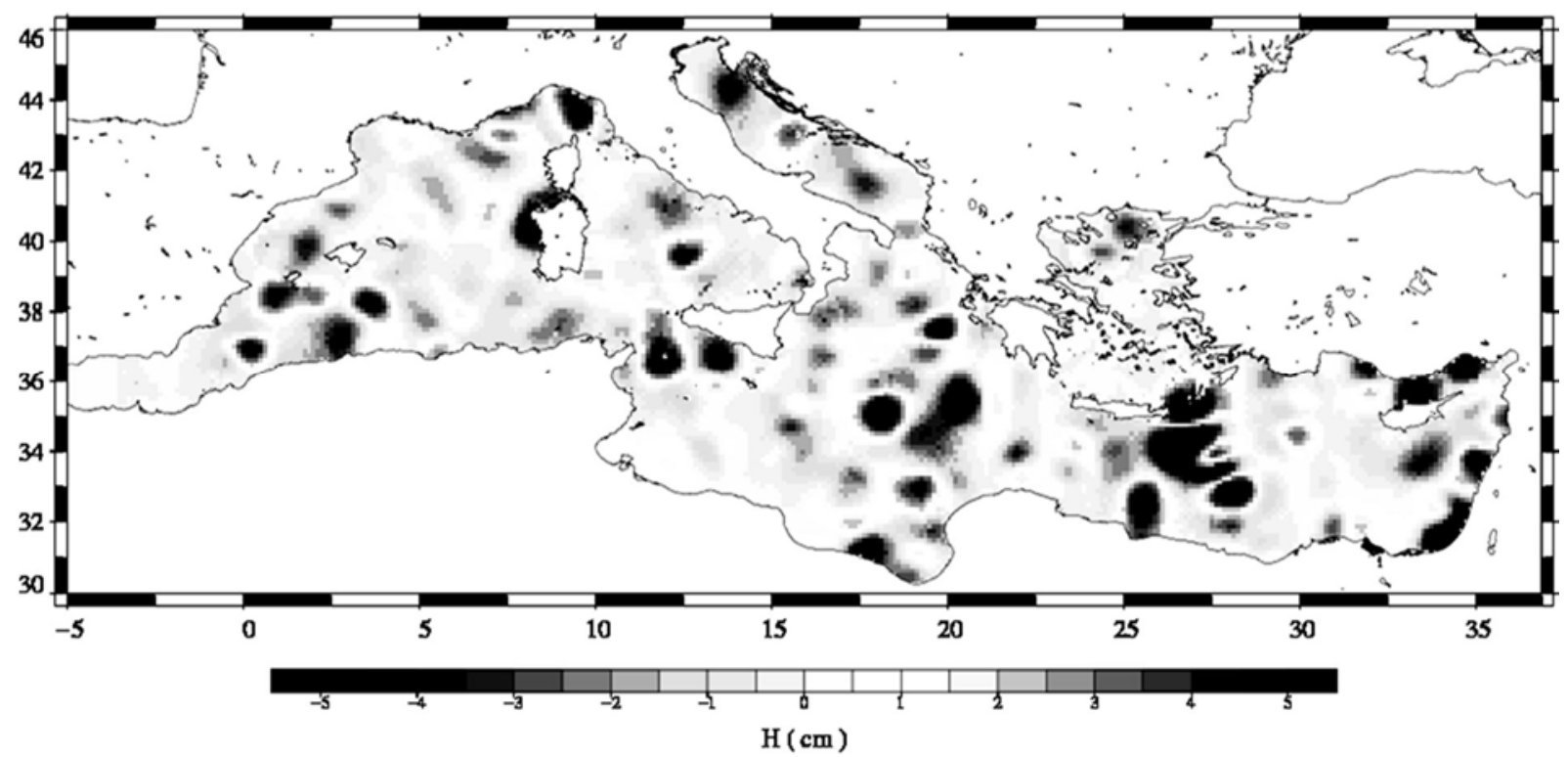


Figure 7: Jason-1/TP interleaved sampling pattern (a) and Jason-2/Jason-1 sampling pattern (b). Black boxes show the date of each track as a day number in the historical cycle (e.g. 5 is the 5th day of the historical TP cycle) for the classic orbit (top row) and the interleaved orbit (bottom row). Arrows show the sampling pattern propagation direction (eastward in grey, westward in black) between neighbor tracks.

a)

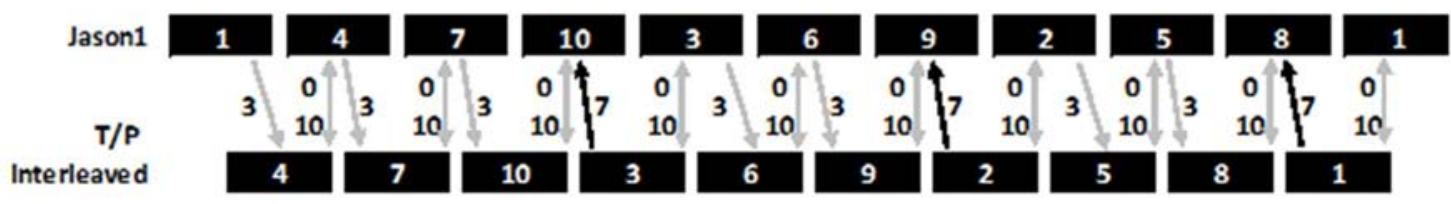

b)

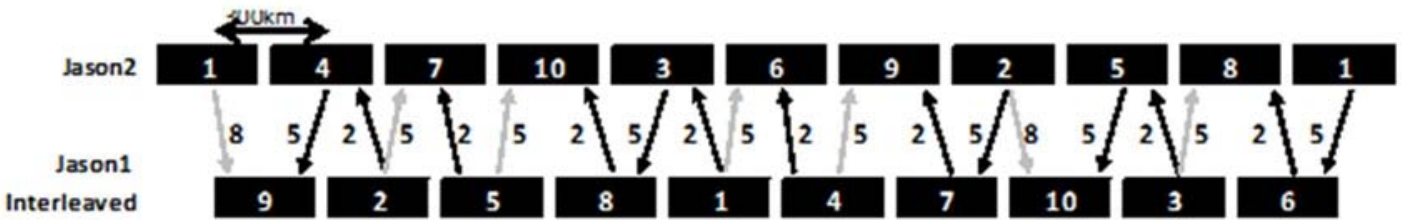


Figure 8 : Multi-satellite maps of the Absolute Dynamic Topography in the Gulf Stream with (right) and without (left) the first 14 days of Jason-1 interleaved data combined to Jason-2. Jason-2 and Jason-1 tandem tracks are superimposed in black and purple respectively.

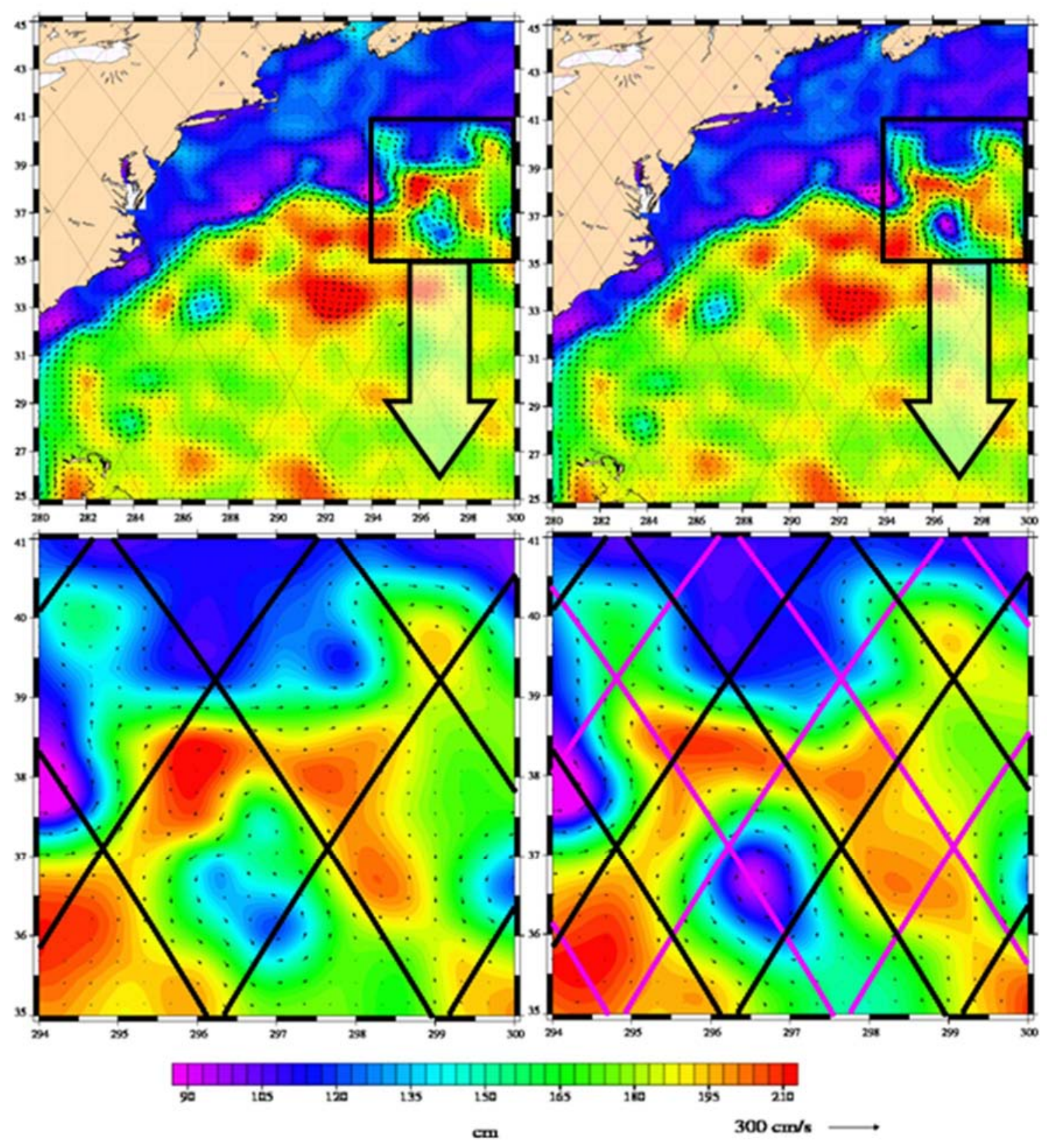


Figure 9 : Map of SLA variance (Spring 2009) derived from Jason-2 + Jason-1 tandem (top) or Jason-2 alone (bottom)

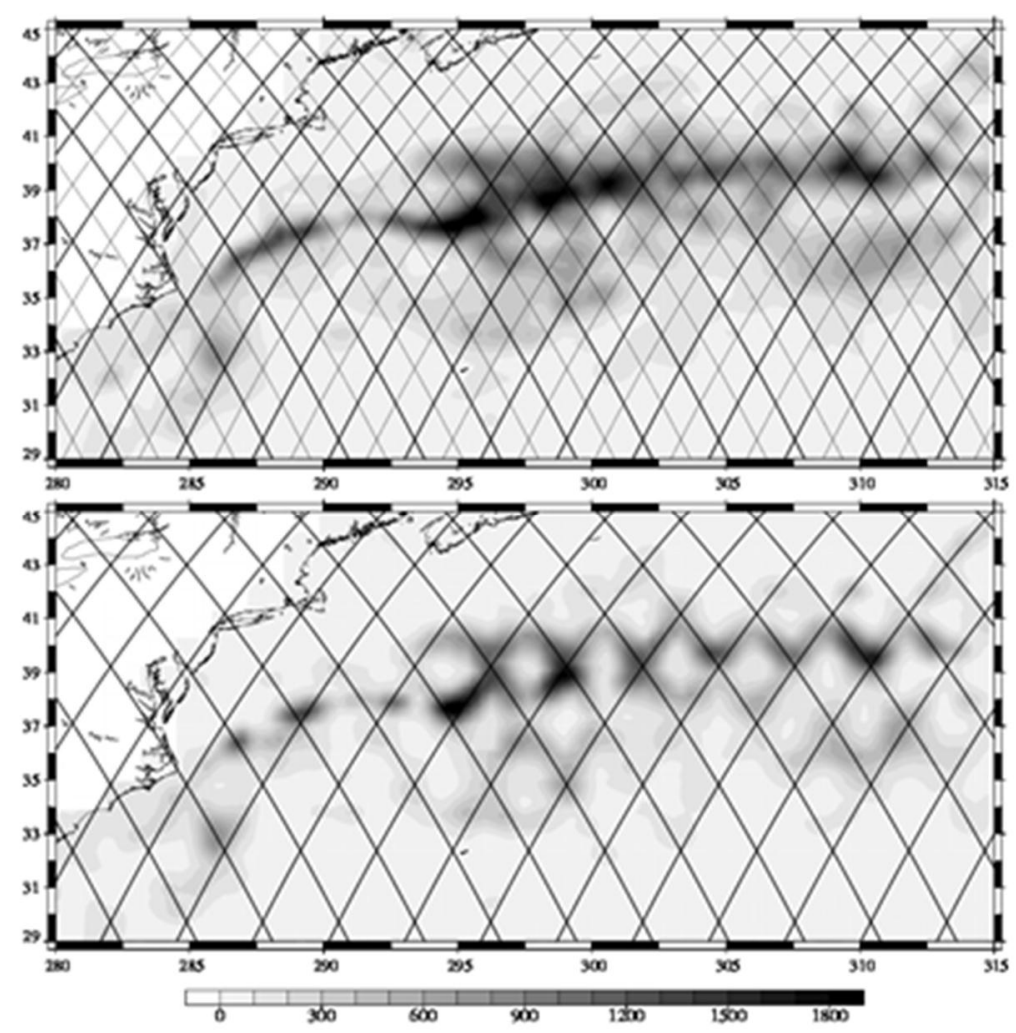

Figure 10 : Unit: $\mathrm{cm}^{2} / \mathrm{s}^{2}$. Evolution of the mean EKE in a $500 \mathrm{~km}$ wide area of the Gulf Stream (derived from Near Real Time maps of SLA). The top figure shows 6 months of Jason-1/TP tandem, and the bottom figure shows 9 months of Jason-2/Jason-1 tandem. The black curve is the EKE of the mono-satellite maps (Jason-1 and Jason-2 respectively) and the grey curve is the EKE of the 2-satellite maps.

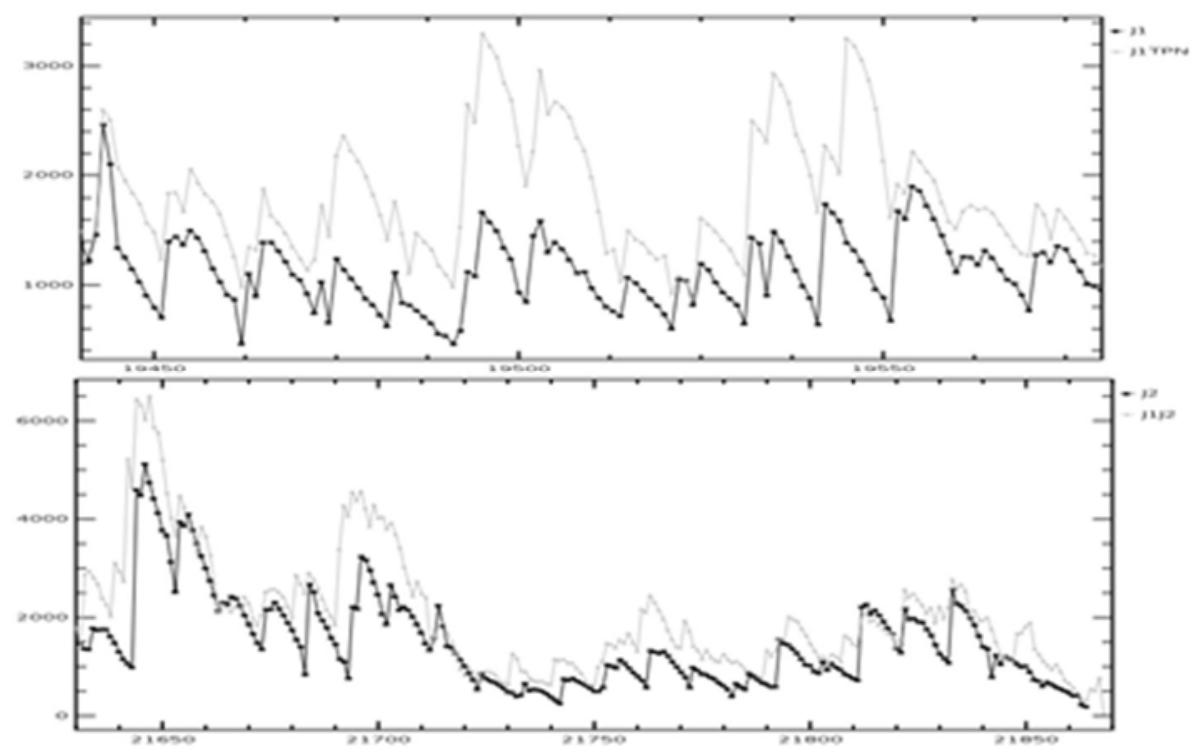


Figure 11 : Fraction of the multisatellite information coming from ENVISAT (left) and Jason-2 (right) and zoom the North Altantic basin (bottom). Computed as the ratio of DFS (i) / Sum(DFS(i)) on each point of a Jason-2+Jason-1+ENVISAT near real time map. Satellite tracks of the last 10 days of NRT data are superimposed as black lines.

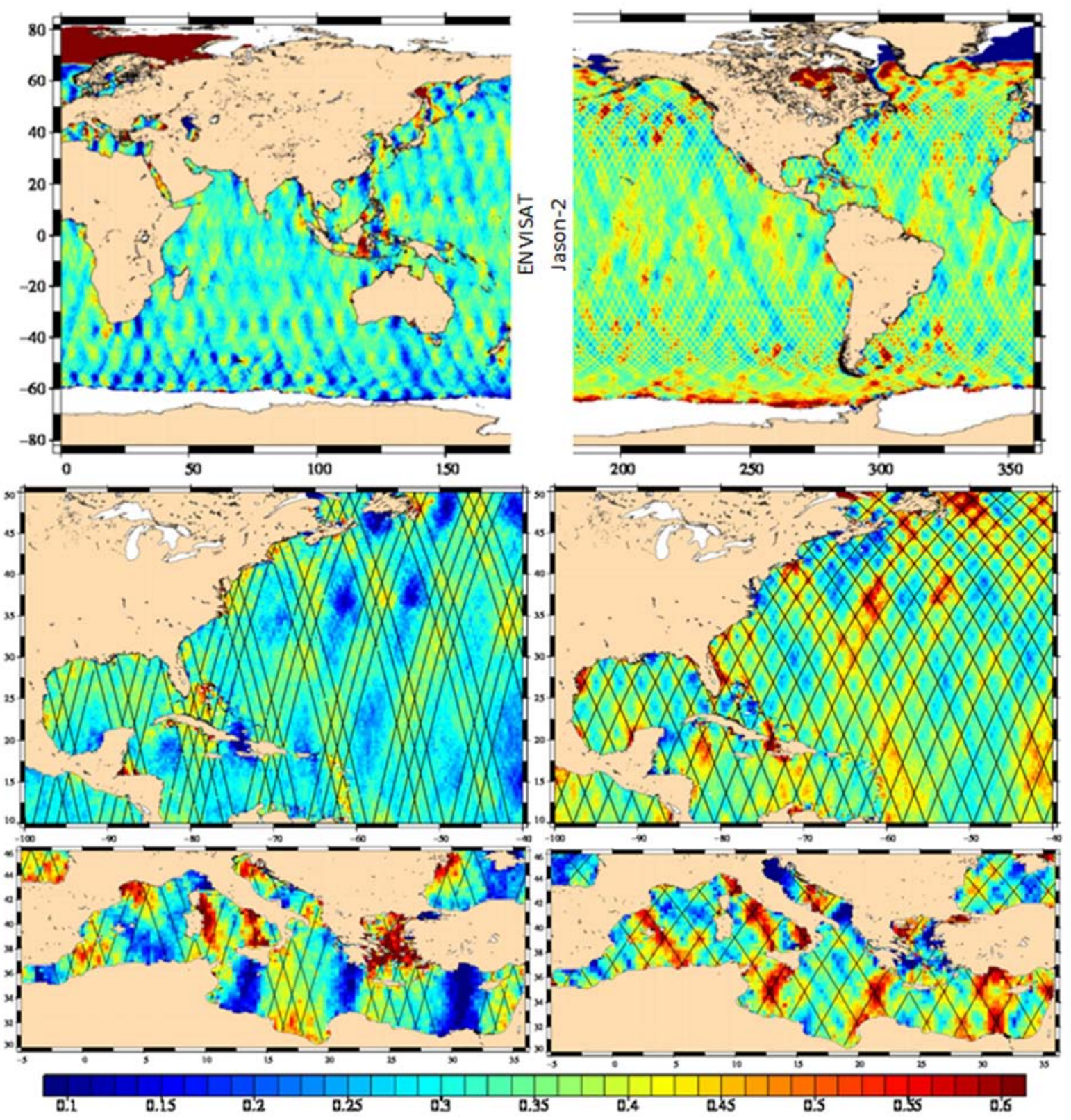


Figure 12 : Coverage improvement associated with the DT-2010 reprocessing. MSLA for day 04/02/2009 in the Southern Ocean for the DT-2007 map (left) and for the DT-2010 reprocessing (right).

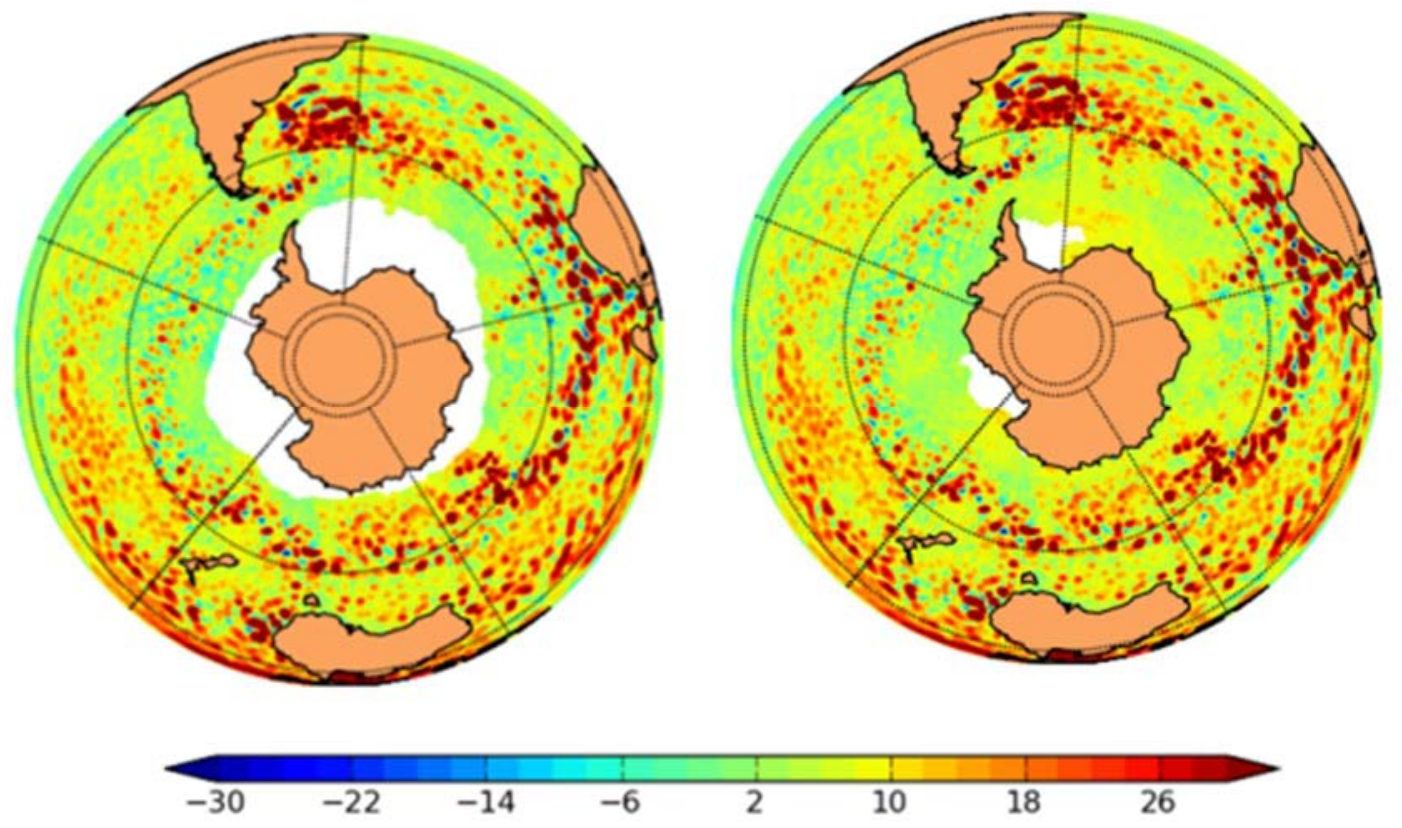

Figure 13 : Along-track Sea Level Anomaly along one arbitrary Jason-1-tandem track (\#159) in the Black Sea. Extended coastal coverage from DT-2007 release (light grey) to DT-2010 reprocessed data set (black). Two consecutive cycles are given: cycle 265 and 266.
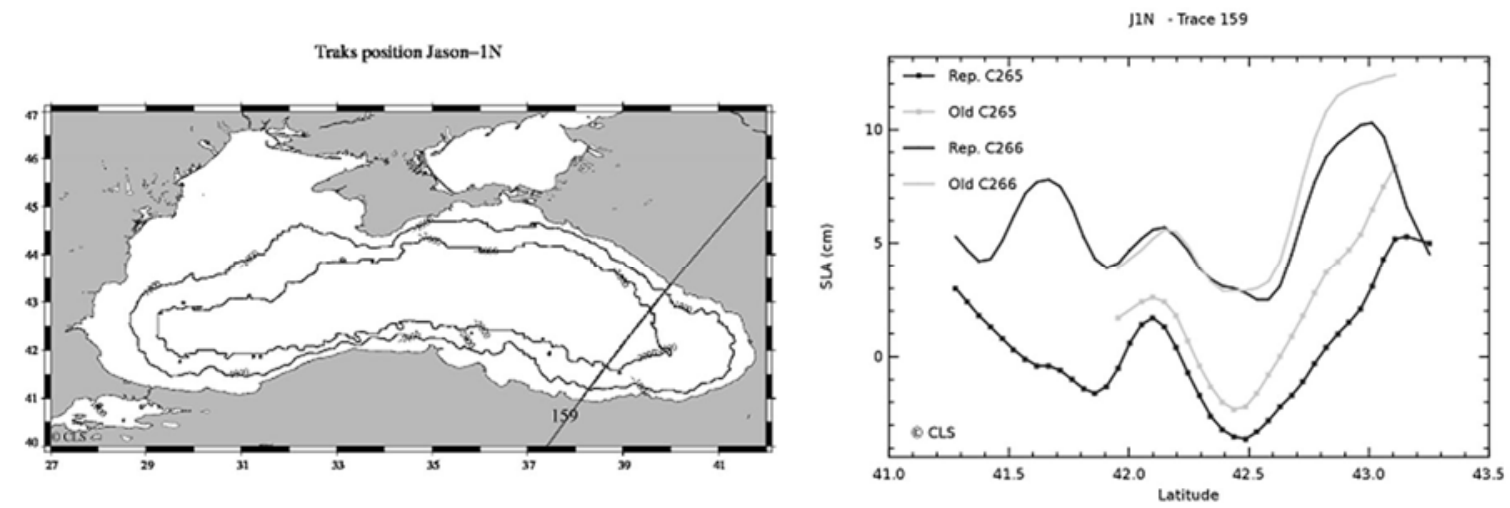
Figure 14 : Difference between the regional sea level trend from Jason-1 (reference mission) and GFO (before cross-calibration).

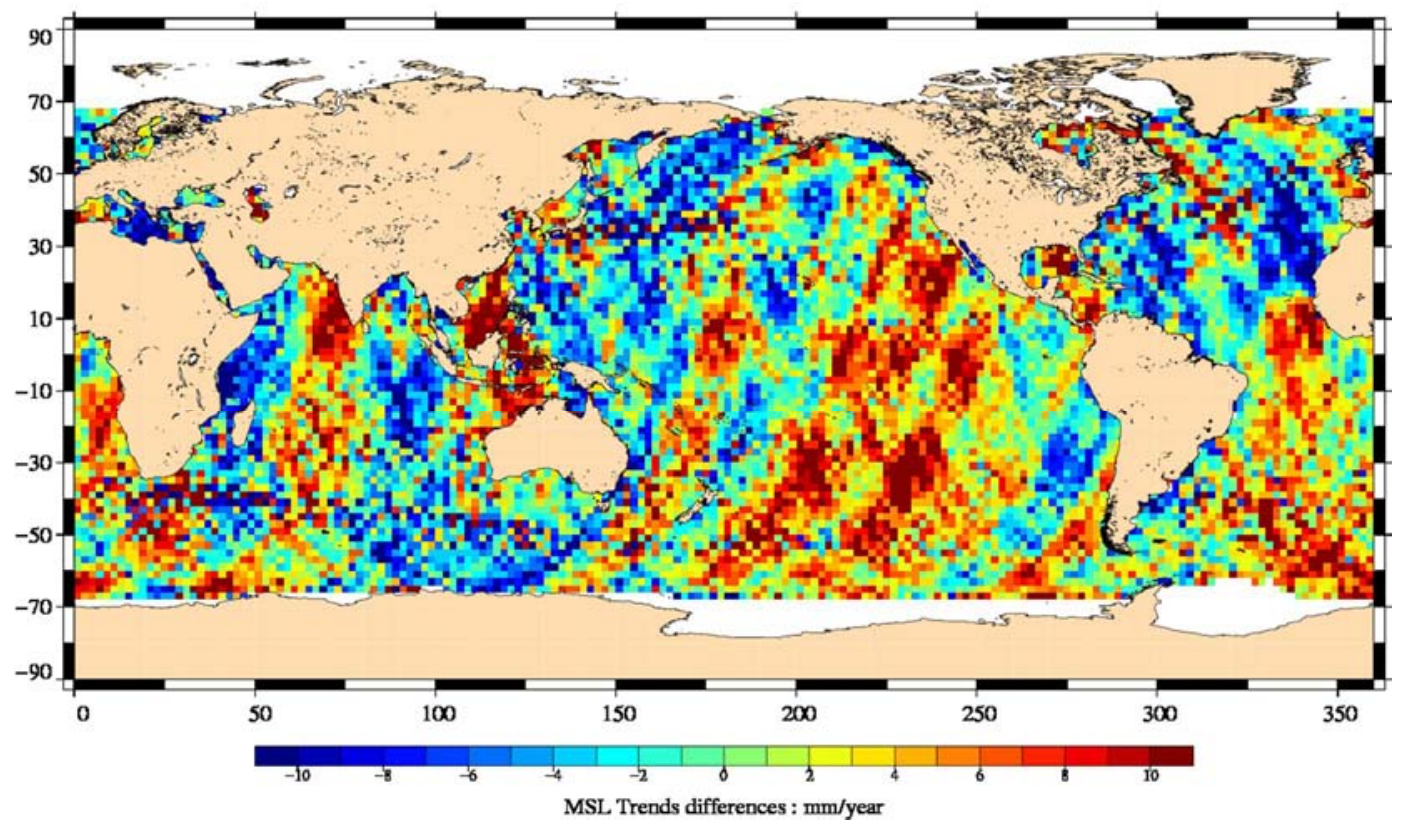

